\title{
Microstructure and Mechanical Performance of Ti-6AI-4V Lattice Structures Manufactured via Electron Beam Melting (EBM): A Review
}

\author{
Giuseppe Del Guercio ${ }^{1}$ Manuela Galati ${ }^{1,3} \cdot$ Abdollah Saboori $^{2,3} \cdot$ Paolo Fino $^{2,3} \cdot$ Luca Iuliano $^{1,3}$
}

Received: 4 August 2019 / Revised: 24 October 2019 / Published online: 17 January 2020

(c) The Chinese Society for Metals (CSM) and Springer-Verlag GmbH Germany, part of Springer Nature 2020

\begin{abstract}
Electron beam melting (EBM) process is an additive manufacturing process largely used to produce complex metallic components made of high-performance materials for aerospace and medical applications. Especially, lattice structures made by Ti-6Al-4V have represented a hot topic for the industrial sectors because of having a great potential to combine lower weights and higher performances that can also be tailored by subsequent heat treatments. However, the little knowledge about the mechanical behaviour of the lattice structures is limiting their applications. The present work aims to provide a comprehensive review of the studies on the mechanical behaviour of the lattice structures made of Ti-6Al-4V. The main steps to produce an EBM part were considered as guidelines to review the literature on the lattice performance: (1) design, (2) process and (3) post-heat treatment. Thereafter, the correlation between the geometrical features of the lattice structure and their mechanical behaviour is discussed. In addition, the correlation among the mechanical performance of the lattice structures and the process precision, surface roughness and working temperature are also reviewed. An investigation on the studies about the properties of heat-treated lattice structure is also conducted.
\end{abstract}

Keywords Electron beam melting $(\mathrm{EBM}) \cdot$ Additive manufacturing $(\mathrm{AM}) \cdot$ Lattice structures $\cdot$ Ti-6Al-4V $\cdot$ Mechanical properties $\cdot$ Heat treatment

\section{Introduction}

The study on Titanium (Ti) alloys started 40 years ago, mainly for the aerospace sector because of the high specific properties of these alloys [1-3]. However, Ti alloys are today considered extremely important for their high corrosion resistance and high biocompatibility for human tissue. The melting point of pure $\mathrm{Ti}$ is around $1670{ }^{\circ} \mathrm{C}$ in which a hexagonal structure $\alpha(\mathrm{HCP})$, stable at low temperature,

Available online at http://link.springer.com/journal/40195.

Abdollah Saboori

abdollah.saboori@polito.it

1 Department of Management and Production Engineering (DIGEP), Politecnico di Torino, Corso Duca Degli Abruzzi 24, 10129 Turin, Italy

2 Department of Applied Science and Technology (DISAT), Politecnico di Torino, Corso Duca Degli Abruzzi 24, 10129 Turin, Italy

3 Integrated Additive Manufacturing Center (IAM) @ Polito, Politecnico Di Torino, Corso Duca Degli Abruzzi 24, 10129 Turin, Italy transforms to a body-centred cubic structure $\beta$ (BCC) which is stable at high temperatures. Ti- $6 \mathrm{Al}-4 \mathrm{~V}$ is a $\alpha+\beta$ Titanium alloy; due to the presence of $\beta$-stabilizing elements such as Vanadium, the transformation is unfinished at room temperature, resulting in a mixture of $\alpha$ and $\beta$ phases [4-6]. It is reported that when the alloy cool down from a complete $\beta$ phase, at a temperature around $995^{\circ} \mathrm{C}$, which is also recognized as the $\beta$-transus temperature, the transformation from $\beta$ to $\alpha$ starts [7]. The kinetics of this transformation defines the final phase composition of the alloy, and accordingly the final properties of the resulted alloy [1]. During the rapid cooling from the temperatures above the $\beta$-transus temperature, the $\beta$ phase transforms to a metastable $\alpha^{\text {c }}$ martensite phase through a diffusionless transformation [1]. It is indeed reported that this diffusionless transformation results in the formation of fine colonies of laths [3].

Focusing on the Ti-6Al-4V alloy, it has been found that a balance of the $\alpha$ and $\beta$ phases is the best way to enhance the mechanical properties [8]. Regarding the production of Ti-6 Al- $-4 \mathrm{~V}$, it is found that the traditional melting techniques like casting suffer from several limitations, such as the necessity to remove high-density inclusions (HDI) 
and low-density inclusions (LDI) to provide composition homogeneity [8]. Moreover, this alloy exhibits high surface oxidation, especially at high temperatures [1]. In the last few years, the scientific community focused on new ways to fabricate the components made of Titanium alloy to reduce the number of aforementioned defects. In particular, additive manufacturing (AM) has shown great potential to be used as one of the most promising fabrication techniques to produce Titanium components [9-11].

AM technologies are defined as "process of joining materials to make objects from 3D model data, usually layer upon layer, as opposed to subtractive manufacturing methodologies" $[12,13]$. This kind of approach allows the production of parts with free design constraint enabling the construction of integrated components, lightweight structures or topologically optimized geometries [14, 15]. Metal AM techniques can be divided into powder bed fusion (PBF) techniques [16-19] and directed energy deposition (DED) techniques [20, 21]. With respect to the PBF systems, DED process has been used not only to produce metallic components [22] but also has been employed to repair the high value parts [23]. PBF systems are systems in which "thermal energy selectively fuses regions of a powder bed" [12, 24]. The main advantages of this kind of approach are the ability to build workpiece with complex details and assure a good dimensional control, due to the excellent resolution of these systems [9]. The most common PBF techniques in the industrial field are laser PBF (L-PBF), also known as selective laser melting (SLM), and electron beam melting (EBM) [25]. Among the metal AM processes, EBM has been already used for mass production for aerospace and medical applications [26, 27]. EBM is able to build complex geometry workpieces with high precision [28-30]. Different materials such as stainless steel [31], tool steel [32], Ni-based superalloys [19], Ti alloys [28, 33] and intermetallics like TiAl [28, 34], particularly for the aerospace, automotive and medical [35] sectors, can be processed via EBM [34]. Among the Ti alloys, today, Ti-6Al-4V alloy is one of the most promising alloys that can be processed via the EBM process.

During the EBM process, an electron beam (EB) with a high power selectively melts the metallic powder. Arcam $\mathrm{AB}$, developed the first EBM system which mainly consists of two main elements: the column in the upper part of the system, and the work chamber in the lower part of the system [36]. The EB is produced by a tungsten filament [37] or a $\mathrm{LaB}_{6}$ crystal located in the column in which an anodic potential of $60 \mathrm{kV}$ is applied. The electrons are accelerated up to $10-40 \%$ the speed of light [38], and they are guided from the top gun towards the working chamber. The EB is controlled by three sets of coils, also called electromagnetic lenses [39]. The first set of coils (astigmatic lenses) controls the shape and the deflection of the electron beam, the second set (focus lenses) controls the focus of the beam, and the last set (deflection lenses) controls the size of the beam [40]. Despite having a small mass, the accelerated electrons have a remarkable amount of kinetic energy, that is converted to heat when the electrons impact the powder bed. This energy ensures the melting of the metallic particles [41].

During the process, the working chamber is maintained under vacuum to avoid the deflection of the electrons due to its interaction with the air molecules. To assure these conditions, EBM systems are equipped with a turbo-molecular pump [41]. The typical residual gas pressures are $10^{-3} \mathrm{~Pa}$ in the working chamber and $10^{-5} \mathrm{~Pa}$ in the column [28]. Unlike the other PBF process, the EBM process starts with a preheating of the powder bed using a defocused EB, high beam current and speed values. The preheating phase sinters the powder bed and facilitates the heat conduction. The typical preheating temperature for Ti-6Al-4V alloy is found to be around $650-700{ }^{\circ} \mathrm{C}[7,42]$. The EBM process is considered as a hot process. In fact, due to the presence of preheating before the melting phase and the vacuum environment, the working temperature in the chamber is approximately equal to the preheating temperature. This aspect ensures small thermal shrinkages and a medium grade of sintering between the particles that results in a specific strength of powder bed [43]. For these reasons, a small number of supports, mainly to distribute uniformly the amount of heat provided during the melting phase, are required to produce the metallic components through the EBM process. After the melting phase, an additional step, called post-heating, takes place [44]. In this step, the layer can be either cooled down or further heated depending on the total amount of energy supplied during the previous steps. Thereafter, the start plate is lowered, and the powder is spread out by the raking system [44], and the process is repeated up to the part is completed. When the construction of the component is finished, the whole part cools down inside the EBM chamber, under a helium flux [45]. After removing the workpiece from the working chamber, the part is entirely covered with a soft agglomerate powder called breakaway powder [45]. To remove this material from the part, a blasting process is required, and to avoid any contamination and accordingly be able to reuse the sintered powder, the same powder processed in the EBM process is employed for the blasting operation [46].

The typical size of residual porosity in the as-built parts processed via EBM is found to be smaller than $100 \mu \mathrm{m}$ [47]. The presence of these pores can be related to the residual gas porosity in the particles from the gas atomization process, lack of fusion and tunnel defects [47]. In some case and depends on the final application, it is required to perform a post-heat treatment like hot isostatic pressing (HIP) to close those residual porosities and improve the definitive characteristics of the part [47-51]. In fact, it should be noticed that the reduction of such defects allows an improvement in the fatigue and compression behaviour of the parts [47]. 
During the EBM process, three main stages can be considered for the Ti-6Al-4V transformation as shown in Fig. 1 [7]. The first stage is characterized by a high cooling rate and leads a diffusionless transformation that transforms the $\beta$ phase in $\alpha^{6}$ martensite. During the second stage, several diffusional transformations change the microstructure into a mixture of fine $\alpha+\beta$ phases at a constant temperature of about $650-700{ }^{\circ} \mathrm{C}[7,42]$. At these temperatures, the diffusion causes the decomposition of the martensite phase $\alpha^{6}$. In the third and last step, the diffusion leads to the microstructure coarsening, with a final microstructure of $\alpha+\beta$ phases with a specific laths size of about $1.4 \mu \mathrm{m}$ [7].

Differently from the EBM, L-PBF techniques do not perform preheating; thus, the temperature after the scanning phase drops immediately up to the ambient temperature. In these conditions, a diffusionless transformation takes place and results in the formation of the martensitic phase. Differently from the EBM process, at the room temperature, the diffusion of the light elements does not occur owing to the kinetic reasons involving in the diffusion process [52]. Therefore, the decomposition of $\alpha^{6}$ does not occur and the final microstructure is characterized by the fine $\alpha^{6}$ martensite [53].

Regarding the EBM process, several studies have been focused on the characterization of the as-built bulk Ti-6Al-4V alloy produced via EBM process and its microstructure modifications by post-heat treatments on bulk material $[49,50,54]$. Apart from the bulk materials produced by the EBM process, micro-architectured or so-called cellular structures could also attract more attention mainly owing to their unique characteristics [55]. In the last few years, these structures have been largely studied, due to the possibility to achieve a design with a unique combination of properties [56] such as mechanical, thermal and acoustic

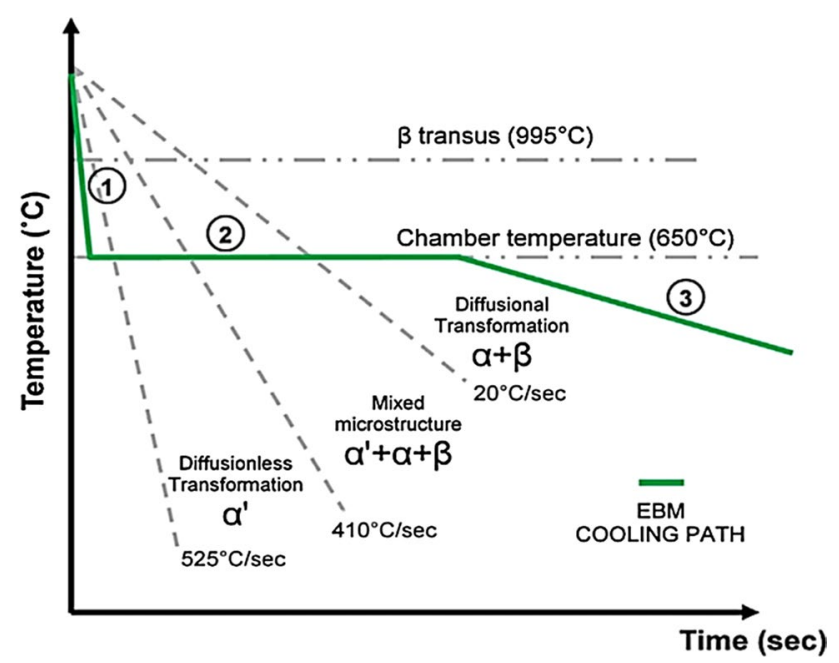

Fig. 1 Thermal evolution in the EBM process [7] properties [57]. As an example, topology optimization design technique has been used to tune the coefficient of thermal expansion (CTE) for the design of high-performance heat exchangers [58]. Among the cellular structures, foams and random topology structures have shown an excellent impact resistance [59]. Differently from the foams, lattice structures belong to the family of cellular materials that do not have an stochastic structure. A lattice structure was defined by Fleck et al. [56] like a cellular, reticulated, truss, mesh arrays or lattice structure made up of a large number of uniform lattice elements and generated by tessellating a unit cell, comprised of just a few lattice elements, throughout the space. A lattice cell consists of a certain number of struts, also called lattice struts, that are jointed in one or more nodes. Therefore, a lattice strut is a link between two nodes. In general, different unit cells can be designed by using different lattice struts between the nodes [55]. The dimensional characteristic of the unit cell is named as the unit cell size. On the other hand, the peculiar dimensions of the struts are the strut size, which represents its diameter, and the strut length, namely the distance between two nodes linked by a strut.

The construction of the lattice structures through the traditional techniques was found to be expensive because of the necessity of the numerous cutting and welding phases required [60]. Hence, EBM technology, which is a layerwise manufacturing process, is considered as one of the most attractive technologies to produce these kinds of structures without supports and using a nesting strategy [55]. A considerable amount of literature has been published on the fabrication and characterization of the lattice structure made of Ti-6Al-4V or Ti-6Al-4V ELI, and it has shown that these components exhibit high specific properties such as specific strength [61], oxidation resistance [61, 62] and biocompatibility for human tissues [62-64]. According to the existing literature, it should be noted that the final characteristics of this kind of structures depend on the design and process [58, $65,66]$. For this reason, several efforts have been carried out to understand and characterize the Ti-6Al-4V lattice structures made by the EBM process [67-73]. The aim of this work is a systematic and comprehensive review of the current state of the art on the mechanical characterization of the Ti-6Al-4V lattice structures produced via the EBM process. To provide this comprehensive overview, the literature was reviewed according to the factors that mainly affect the mechanical behaviour of the lattice structures. Afterwards, the effective aspects were categorized considering the EBM process at the centre of the characterization.

All in all, the main steps to produce an EBM part were considered as guidelines to review the literature on the lattice performance: (1) design, (2) process and (3) post-heat treatment. For the aforementioned reasons, the paper was organized as follows. At first, the effect of the design of the 
lattice structure on its mechanical properties was reviewed. Then, the effect of relative density obtained by different lattice design was discussed, as well as the models to forecast the lattice properties. Thereafter, the effect of the precision of the EBM process on the lattice structure was investigated, especially looking for the deviation between the design and the actual structure. At the end, the role of heat treatments on the mechanical properties of the Ti-6Al-4V lattice structures was analysed.

\section{Mechanical Behaviour of Ti-6Al-4V Lattice Structures made by EBM}

The properties of cellular materials extend the range of available features for the design of new components.

Figure 2 shows the variation of the range of design properties reported by Ashby and Gibson [55]. Moving from solids to foams, the presence of air gaps inside the material causes a reduction of density, conductivity, Young's modulus and strength. Ashby identified three main factors that influence the properties of cellular materials: (1) material of which is (a)

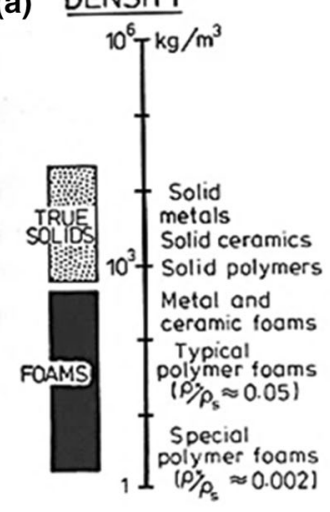

(c) YOUNGS MODULUS

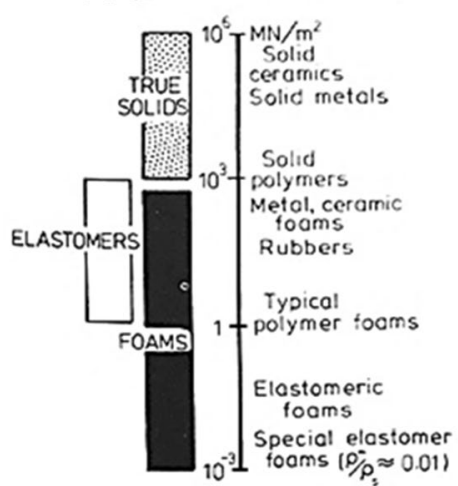

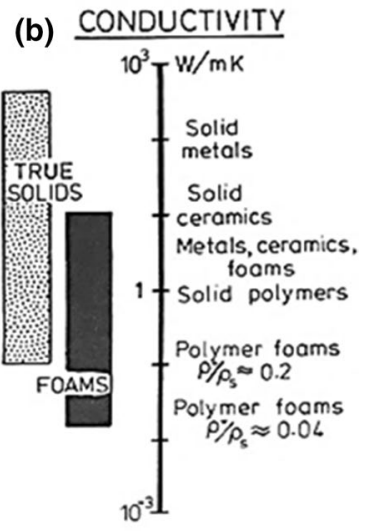

(d) STRENGTH

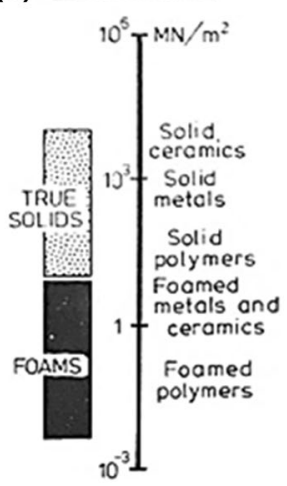

Fig. 2 Range of properties available to the engineer through foaming: a density; b thermal conductivity; c Young's modulus; $\mathbf{d}$ compressive strength [55] made, (2) cell topology and shape and (3) relative density [74]. The first factor affects the mechanical, thermal and electrical properties. Cell topology and shape are relevant to the behaviour distinction between bending and stretching-dominated structures [75]. The relative density, which is the ratio between the density of cellular material $\rho^{*}$ and the density of the bulk material $\rho_{\mathrm{s}}$, is the parameter that defines the general properties of the cellular structures [55].

In another work, Deshpande et al. [75] introduced the classification of cellular materials according to their collapse response under the load. This classification distinguished the structures into bending-dominated or stretching-dominated. In bending-dominated structures, the behaviour of the cellular material is based on the rotational stiffness and strength of nodes and struts [56]. In fact, it is found that foams exhibit most likely a bending-dominated behaviour, while the lattice can be both stretching-dominated and bending-dominated materials [75]. The macroscopic behaviour of a lattice structure, therefore, depends on the axial stiffness and strength of the struts [56]. Maxwell studied the equilibrium and stiffness of the frames [76] and provided a criterion to discern stretching and bending-dominated structures, which have been already validated by the studies of Deshpande et al. [75]. According to this criterion, in a 2D rhombic structure if a longitudinal beam is inserted, the vertical stiffness of the frame is given by the axial stiffness of the longitudinal beam itself [76].

Murr et al. [61] studied cellular structures with a specific aim to investigate their mechanical properties and microstructure in the as-built condition. In their work, the microstructure of the foams and lattice structures were studied in deep by means of scanning electron microscopy (SEM) analysis. The outcomes showed a high quantity of the $\alpha^{\text {c }}$ martensite, given by the rapid solidification which is taken place in the cellular solids. Indeed, it is revealed that the presence of large air gaps between the struts results in a very high cooling rate and thus rapid solidification.

Recently, Murr et al. [73] evaluated the differences between the microstructure a fully dense and foam specimens. In comparison with their previous work [61], the aim of this current work was to investigate the differences between cellular solids and bulk specimens [73]. As can be seen in Fig. 3, the microstructure of the bulk material is characterized by a coarse mixture of $\alpha$ and $\beta$ phases, whereas the foam shows a finer microstructure with a presence of $\alpha^{6}$ martensite. Moreover, they confirmed that the topology of the material has a big impact on the final phase composition of cellular structured part [73].

\subsection{Compressive Behaviour of the Lattice Structure: Experimental and Numerical Models}

The first model to describe the performance of a generic cellular material as a function of its relative density is proposed 

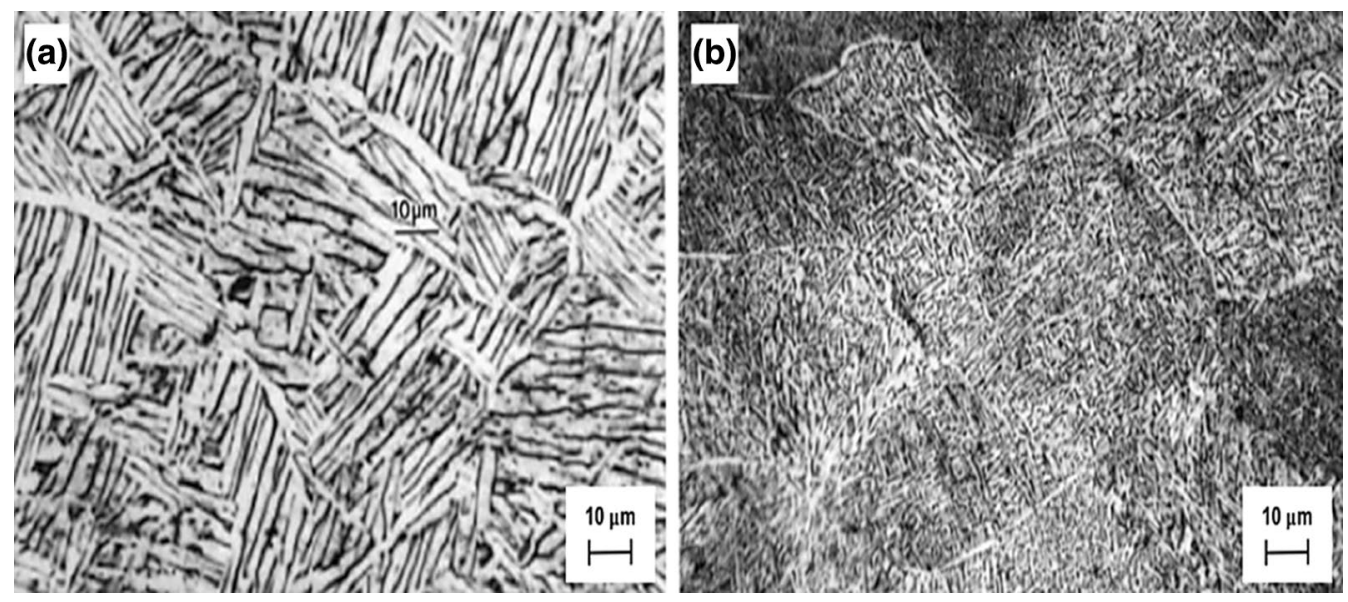

Fig. 3 Optical micrographs showing different microstructures for a a bulk material, b a foam [73]

by Ashby and Gibson [55]. Considering the mechanical performance under compressive load, one of the most important properties to estimate is the compressive Young's modulus of the material. Therefore, the following equation which is proposed by Ashby and Gibson can be employed to evaluate this mechanical characteristic of the material [55]:

$\frac{E^{*}}{E_{\mathrm{S}}}=C_{1}\left(\frac{\rho^{*}}{\rho_{\mathrm{s}}}\right)^{2}$

where $E$ and $\rho$ are the Young's modulus and the density of material, respectively. The star labelled values are referred to the cellular material, while the ones sub- $s$ is referred to the bulk material. Moreover, it should be noted that $C_{1}$ is a constant in this relationship. However, in the lattice structures, despite an slight effect of the cell size on the $C_{1}$ value, $C_{1}$ is usually assumed to be equal to $1[55,59,64]$. Another important property is the Ultimate Compressive Strength (UCS), which can be evaluated through the following relationship:

$\frac{\mathrm{UCS}^{*}}{\mathrm{UCS}_{\mathrm{s}}}=C_{5}\left(\frac{\rho^{*}}{\rho_{\mathrm{s}}}\right)^{3 / 2}$

where $C_{5}$ is an empirical constant which should be determined experimentally. Murr et al. [61] assumed a $C_{5}$ value equal to 1.5 , while in another work, this value is reported 2.2, which is almost $50 \%$ higher than the assumption of Cheng et al. [66]. These variations in the $C_{5}$ values can be explained by using different cell types in their works.

In another research, Murr et al. [61] showed that while the foam behaviour is well described by its relative density, the lattice properties are also influenced by the topology and dimensions of the unit cell.

Differently, Cheng et al. [66] investigated the differences between the mechanical properties of lattice and foams.
They, indeed, evaluated the compressive behaviour of two cellular solids with two different topologies: a foam and a lattice structure with rhombic dodecahedron shape. It is revealed that, in the case of lattice sample, a brittle fracture with crush bands at an angle of approximately $45^{\circ}$ was taken place, whereas in the foam sample the failures occurred at random angles. The specific strength of lattice structures has been found to be higher than the foams with the same specific stiffness. This result occurs due to the microstructural difference between the foams and lattice samples. Indeed, as mentioned earlier, lattice structures characterized by fine $\alpha$ martensite, while foams show a coarser $\alpha+\beta$ microstructure.

Both Murr et al. [61] and Cheng et al. [66] evaluated the Young's modulus of lattice structures at different relative densities using the resonant frequency method and the damping analysis. Similar to the Ashby-Gibson model, lattice structures followed a linear law in a logarithmic scale graph with different exponents. On the other hand, Hernàndez-Nava et al. studied the effects of density and feature size on the mechanical properties of lattice structures [77]. They found that only for specific structures the Ashby-Gibson model for the prediction of Young's modulus and the compressive strength can be accurate enough to model the behaviour of the structure [77]. Differently, Mortensen et al. [78] proposed an analytical approach in which the porous structure is designed by interpenetrating spheres that simulating the pores where the porosity variations were obtained just moving the centres of the spheres. Since the topology of the structure has not been changed, the increase in the strut size entails an increase also in the Young's modulus and the UCS. Similarly to Mortensen et al. [78], Horn et al. [79] suggested a modification of the Ashby-Gibson model, specifically for the compressive behaviour of lattice structure made by rhombic dodecahedron open cells. In their work, three sets of specimens with different cell sizes were investigated in order to evaluate the effect of size. The strut size 
was changed to evaluate the effect of relative density and strut thickness for each batch of samples. Differently from the previous analysed works, flexural tests were conducted to evaluate the relative Young's modulus with respect to the relative density. From the analysis of the results, it is revealed that the Ashby-Gibson relationship is a proper approximation for the experimental behaviour.

Horn et al. [79] also presented two useful charts that collected a considerable number of experimental data from literature regarding the mechanical characterization of cellular structures (Fig. 4). Both on the relative modulus of elasticity (Fig. 4a) and on the relative UCS (Fig. 4b) laws are similar to Eqs. (1) and (2) that implied the achievement of an acceptable forecast. Experimentally, Cansizoglu et al. [68] evaluated the behaviour under uniaxial compressive conditions (to evaluate the UCS) and flexural conditions (to evaluate Young's modulus) of the honeycomb lattice structures with different strut sizes [68]. A linear law in a logarithmic scale graph between the mechanical properties and relative density was detected. The same kind of relationship between the relative density and both the relative UCS and Young's modulus was shown to exist also by Parthasarathy et al. [67]. In their study, a cubic lattice structure was analysed by four sets of specimens with different pores and strut sizes, with an overall designed porosity ranging from 60.91 to $75.83 \%$. They stated that the difference between the Ashby-Gibson model and the experimental results occurred due to the size of the specimens used for the experiments. In fact, the Ashby-Gibson model for cellular solids [55] assumed a structure with an infinite number of pores. Practically, such structure could be obtained only reducing the dimensions of the cell that may be incompatible with the EBM process due to the process precision $[67,79]$ and also to the necessity of powder removal from the fine cells [45, 79]. The differences between theoretical and experimental results could also be explained by the irregularities and corrugations of the surface of struts [67] that will be discussed further. To predict the elastic modulus of porous lattice structures, a finite element analysis (FEA) model based on the volume element method (RVE method) [80, 81] was developed by Parthasarathy et al. [82]. The design of the lattice structures adopted in the application of the RVE method was as same as the previous work [67], and the results showed that for porosities ranging from 28.18 to $78.14 \%$, the relative elastic modulus progressively decreases (Fig. 5).

The comparison between numerical and experimental results showed a better prediction of Young's modulus at high relative density, meaning a more precise model response for lattice structure with a low porosity content. The compression results showed that lattice structures with graded porosity can be employed in the craniofacial implants and hip implants [74]. Compressive strength for the diamond lattice structures with graded porosity was evaluated by van Grunsven et al. [69]. Four sets of the structure were produced; for three of them, a fixed unit cell side length was used. Different relative densities were obtained only varying the strut thickness. The last design was made by three layers with a height of $2 \mathrm{~mm}$ per layer and made of one of the previous designs to obtain a graded porosity structure. An increase in both compressive strength and Young's modulus with the relative density and the strut thickness was revealed.
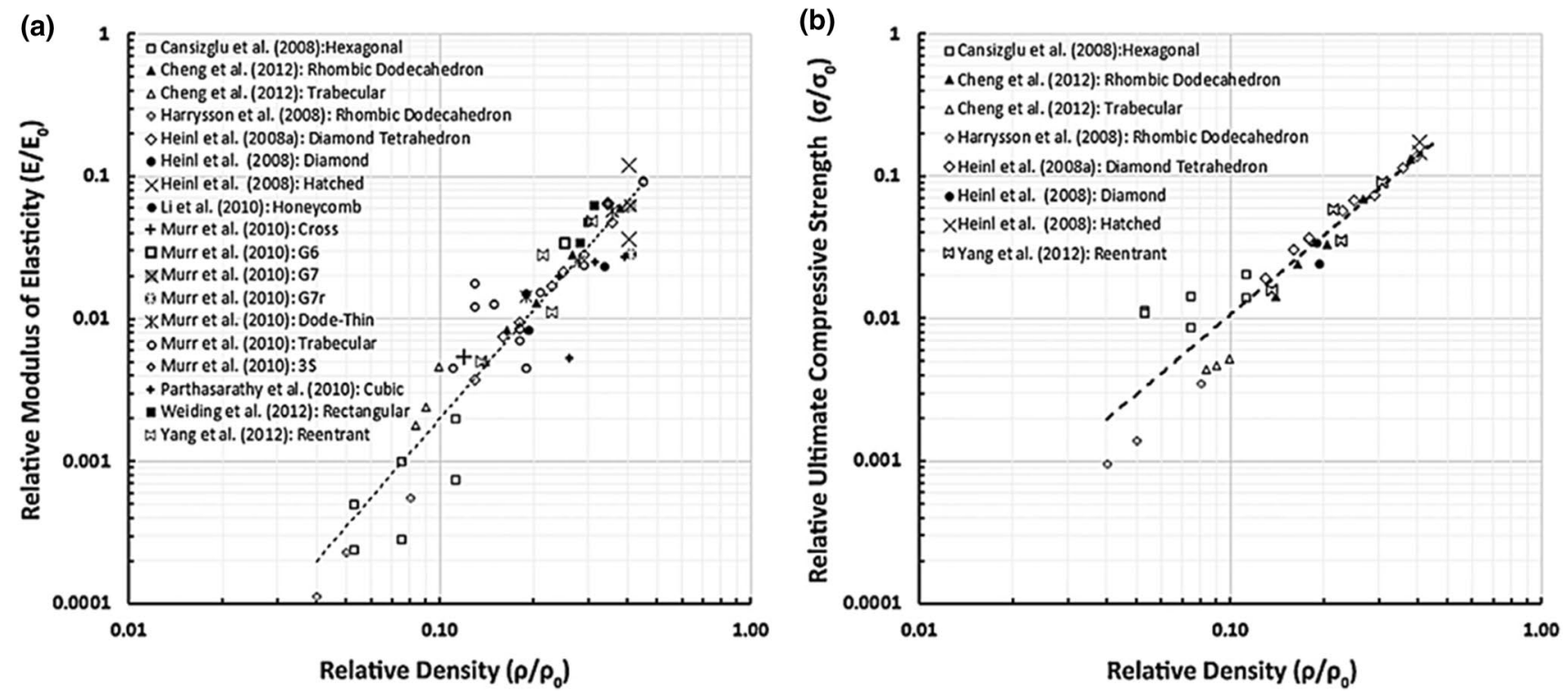

Fig. 4 Charts summarizing the relationship between relative density and relative modulus of elasticity a and relative compressive strength $\mathbf{b}$ derived from Ti-6Al-4V cellular structures [79] 


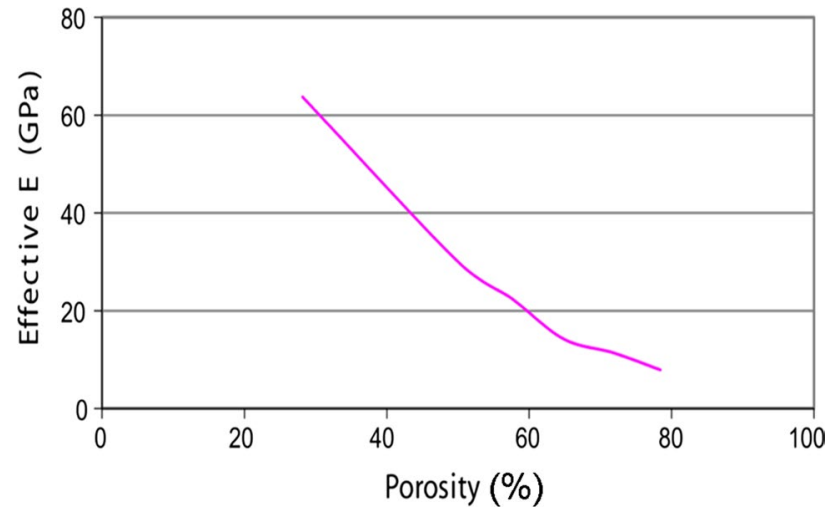

Fig. 5 Variation of effective $\mathrm{E}$ as a function of porosity [82]

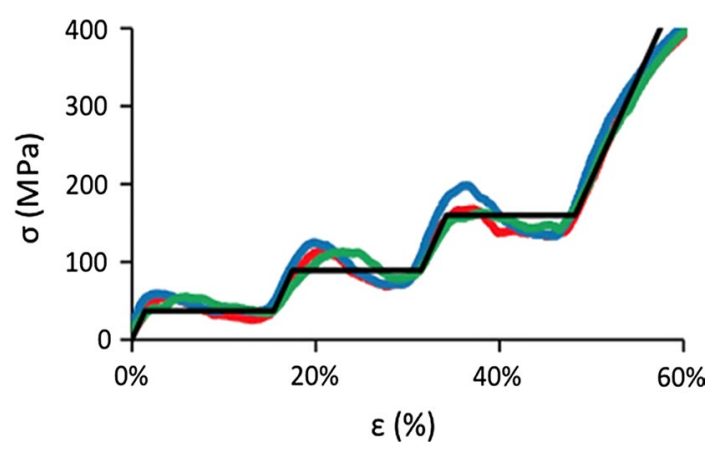

Fig. 6 Mechanical behaviour of the graded lattice structure [69]

The stress-strain curves of graded lattice specimens are shown in Fig. 6. The black line indicates the predicted form of the stress-strain curve calculated upon the data obtained from the tests conducted on uniform lattice structures, while the coloured lines indicate the stress-strain curves obtained for all the three graded specimens. All curves showed a clear collapse on the individual layer. A formulation for predicting the Young's modulus of a graded lattice structure has been proposed assuming a simple series of uniform layers of the same thickness. In the iso-stress conditions that correspond to axial compression, the rule of the mixture has been applied to calculate the elastic modulus of the whole structure [69]:

$\frac{1}{E_{\text {graded }}}=\frac{1}{3 E_{1}}+\frac{1}{3 E_{2}}+\frac{1}{3 E_{3}}$.

In Eq. (3), $E_{\text {graded }}$ is the Young's modulus of the graded lattice structure, whereas $E_{1}, E_{2}$ and $E_{3}$ are the Young's modulus of each layer of the whole structure. This result is useful in the design of orthopaedic implants in which the possibility to tune the mechanical characteristics and the relative density according to the properties of the actual bone structure could be a turning point for this kind of applications in the medical sector.

Remaining in the medical application field, Heinl et al. [65] studied cross and diamond unit cells with interconnected macroporosity made by EBM for the bone implants applications. Differently from the previous analysed studies, they were focused on the effect of chemical surface modification on the mechanical behaviour and biocompatibility features of lattice. For the bioactivity test, several chemical etchings were performed. The derived results showed the apatite formation in simulated body fluid under dynamic conditions that provided better fixation of the implant in the prior tissues and bones. Cross-unit cell structures showed better mechanical characteristics due to lower porosity content with respect to diamond structures. This result is consistent with the Ashby-Gibson model [55]. In addition, the values of elastic modulus were found to be coherent with human bone values.

Moving to the dental application field, Jamshidinia et al. [71] studied three different unit cells (cross, honeycomb and octahedral) with different cell sizes. The aim of their work was to provide a dental abutment with specific elastic micro-motion. Larger size caused an increase in total elastic deformation and, therefore, the higher elastic modulus could be obtained by using smaller dimensions. Comparing the results between the different unit cells types, the honeycomb is the stiffer lattice while the least stiff structure is the cross-unit cell. This result occurs because the cross-unit cell-shaped lattice structures show a higher number of stress concentration points with respect to the lattice structures made of other unit cell types.

Jamshidinia et al. [71] also proposed a numerical simulation to predict the mechanical response at different angles of load. The numerical results showed that for angles above $30^{\circ}$, the maximum stress decreases. This phenomenon was explained as a failure of the structure when the higher stress levels are over the yield stress. In another work, the fatigue properties of cellular structures have also been investigated [83]. The experimental results showed that with the increase of the load, the life of the specimens decreases. The comparison between the experimental and numerical data suggested that the best way to correct the mean stress is the Soderberg relationship [83]. According to the numerical results, the sharp corners of the structures are the most stressed points. The reduction of fatigue life is suggested to occur much frequently with high levels of surface roughness, especially in lattice structures with a small strut size.

Epasto et al. [84] studied rhombic dodecahedron lattice structures and the effect of unit cell size. After the conduction of the compressive tests, it was possible to conclude that with a decrease of the cell size both the compressive strength and Young's modulus increases. It is found that this result is a consequence of a reduction in the cell size and accordingly 
increases of the relative density of the whole material. Thus, since lattice structures follow the Ashby-Gibson relationship, an increase in both compressive strength and Young's modulus is expected [55].

Table 1 collects all the testing conditions of the mechanical tests conducted in the literature. As discussed earlier, the conducted experiments cannot be easily compared because of using the different standards, different structure and different ultimate load conditions in different studies. However, the main findings of all the investigated studies confirmed that the lattice properties are influenced by the design and dimensions of the unit cell, as stated earlier by Murr et al. [39]. Most of the analysed paper used the relative density as the key parameter that defines the mechanical behaviour of a lattice structure. Figure 7 collects the results found in terms of Young's modulus from the analysed works according to the Ashby and Gibson model, which confirm a net relationship with respect to the relative density [55].

\subsection{Effect of Working Temperature on the Compression Behaviour of the Lattice Structure}

As far as the impact of the working temperature is concerned, Xiao et al. [70] analysed the respond of open-cell rhombic dodecahedron structure. Their study also examined the effects of the ratio between the length $(l)$ and the diameter $(d)$ of the struts. Two different configurations were studied: in the first one, the previous mentioned $l / d$ ratio is equal to 2.5 , whereas in the second one $l / d$ is equal to 1.5 .

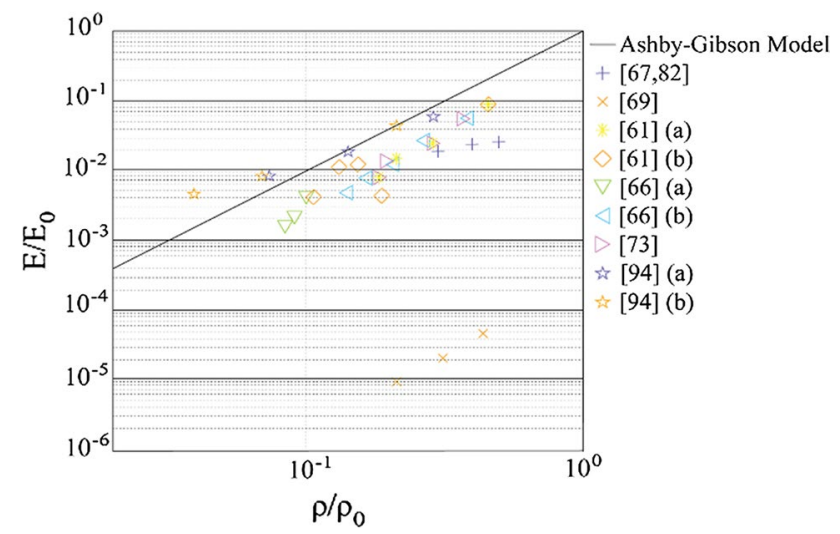

Fig. 7 Experimental results for relative Young's modulus from literature

The specimens were produced with an Arcam A2 system and then were tested with the same quasi-static compressive conditions at room temperature, $200{ }^{\circ} \mathrm{C}, 400{ }^{\circ} \mathrm{C}$ and $600{ }^{\circ} \mathrm{C}$, respectively. A high-temperature furnace was used to regulate thermal conditions.

Figure 8 shows the room temperature nominal stress-strain curves of lattice structures under uniaxial compression, which is also detected in other studies $[66,72,86]$. The curves can be divided into three main segments. The first part is the elastic behaviour of the lattice structure, and the second one represents the progressive collapse of the layers up to when the structure has the same behaviour of the bulk material that is visible in the last part of the graph. The

Table 1 Testing conditions for compression tests conducted in literature

\begin{tabular}{|c|c|c|c|c|c|}
\hline References & Test typology & Adopted standard & Ultimate load condition & $\begin{array}{l}\text { Strain velocity } \\
(\mathrm{mm} / \mathrm{min})\end{array}$ & Strain rate $\left(\mathrm{s}^{-1}\right)$ \\
\hline$[67]$ & Compression & ASTM D695-02 & Until failure & 1 & \\
\hline \multirow[t]{2}{*}[68]{} & Compression & & & 5 & \\
\hline & Flexural & & & 1 & \\
\hline$[69]$ & Compression & & Until $50 \%$ of the original size & 0.25 & \\
\hline$[57]$ & Compression & & $100 \mathrm{kN}$ & & \\
\hline$[70]$ & Compression & & Until total strain exceeded $65 \%$ & 0.9 & 0.001 \\
\hline$[85]$ & Compression & & $50-5 \mathrm{kN}$ & & \\
\hline [71] & Compression & & $400 \mathrm{~N}$ & & \\
\hline [48] & Tensile & ASTM T8 & & & 0.0044 \\
\hline$[82]$ & Compression & ASTM 695-02 & Until failure & 1 & \\
\hline [66] & Compression & & & & 0.001 \\
\hline$[65]$ & Compression & ASTM E9 & & 0.5 & \\
\hline [79] & Flexural & ASTM F2921 & & 2.54 & \\
\hline \multirow[t]{2}{*}{ [77] } & Compression & & & & 0.0002 \\
\hline & Flexural & ASTM C1684-13 & $5 \mathrm{kN}$ & & 0.0022 \\
\hline \multirow[t]{2}{*}{ [86] } & Compression & & & 0.9 & 0.001 \\
\hline & Hopkinson bar & & & & $10^{2}-10^{4}$ \\
\hline
\end{tabular}



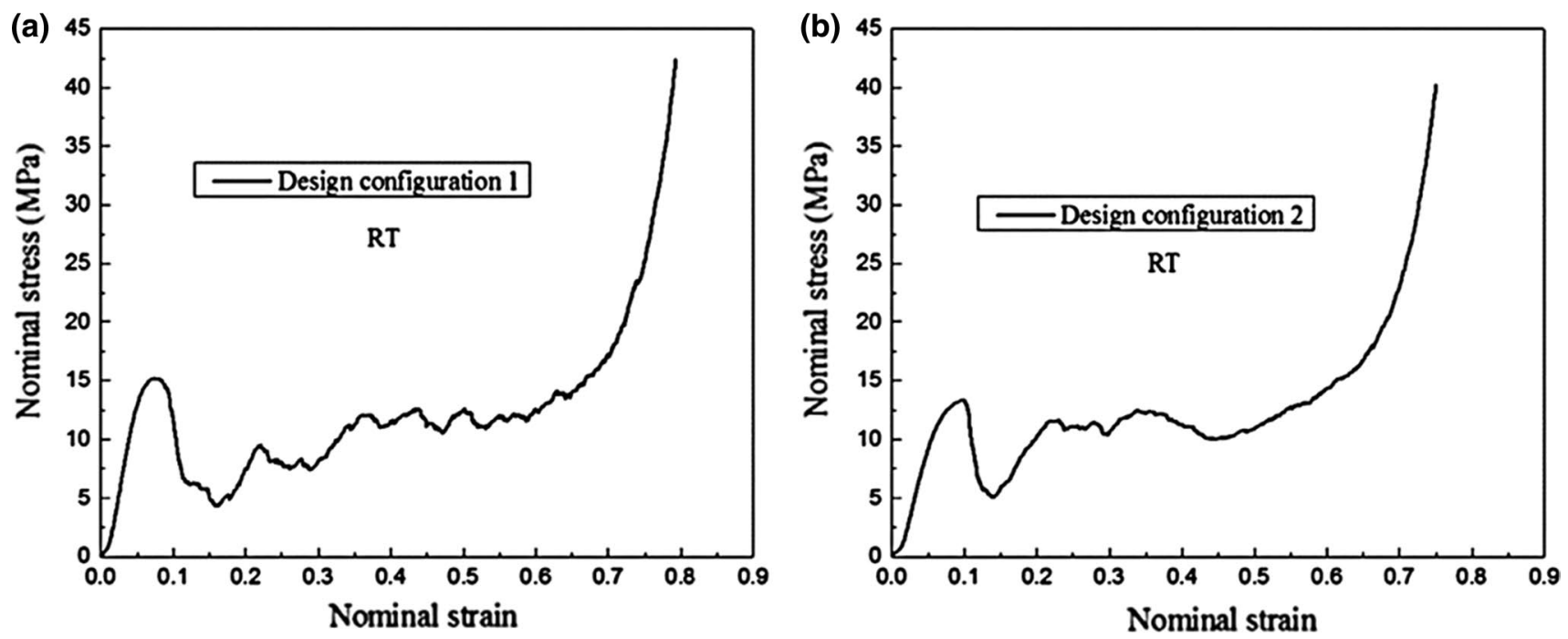

Fig. 8 Nominal stress-strain curves for configuration 1 with an $l / d$ ratio of $2.5 \mathbf{a}$ and configuration 2 with an $l / d$ ratio of $1.5 \mathbf{b}$ [70]

typical brittle failure of the specimens with $45^{\circ}$ is reported by Cheng et al. [66].

The same compression tests were also conducted at different temperatures, and the resulted stress-strain curves are shown in Fig. 9. As can be seen, the increase in the temperature causes the curves to become smoother, and the plateau stress decreases. This result can be explained by the thermosoftening behaviour of the material and a change of failure mode. As mentioned earlier, at room temperature lattice structure shows a brittle response with failures at $45^{\circ}$. With the increment of the temperature, the specimens did not show a clear fracture angle; random failure surfaces were indeed detected. As far as the effect of the size is concerned, the performances of the structure with the larger cell size (configuration 1) are worse than the ones with the smaller cell size (configuration 2) for both elastic modulus and collapse strength. According to the Ashby-Gibson theory, this behaviour is explained by the lower relative density of the structure with larger cell size.

\subsection{Hardness}

The hardness characterization of titanium made lattice structure has been rarely investigated in the literature. Cheng et al. [66] investigated the hardness of lattice and foam ligaments (or struts). Hardness tests were conducted on both foam and lattice specimens with different strut size. As it is possible to see from Table 2, an increase in Vickers hardness occurs with the decrease of the strut size. Their optical observation indicated that the microstructure of foams is finer than the lattice structures. This result suggests that foams were subjected to a faster cooling rate process with respect to the lattice structure. The cooling rate increases with the decrease of ligament/strut thickness; thus, it was possible to conclude that with a reduction of thickness of the ligament/strut, a finer microstructure forms that consequently increases the cell hardness. Moreover, it is found that in the microstructure of the mesh samples a small amount of $\beta$ phase surrounded by the acicular $\alpha^{\prime}$ martensite (Fig. 10).

\subsection{Behaviour of the Lattice Structure Under Cyclic Loads: Fatigue Investigations}

The influence of loading frequency between 2 and $30 \mathrm{~Hz}$ on implant failure under cyclic fatigue conditions was investigated by Karl and Kelly studies [87]. The experimental results showed that fatigue failures occurred more likely at low loading frequencies. On the other hand, no particular effect was found regarding the loading magnitude. After the conduction of Weibull and SEM analyses, it was possible to understand that damage accumulation is the primary failure mechanism for fatigue behaviour of lattice structures.

$\mathrm{Li}$ et al. [72] investigated the compression fatigue behaviour at different load levels of rhombic dodecahedron unit cells lattice structures with a range of density between 0.73 and $1.68 \mathrm{~g} / \mathrm{cm}^{3}$. Figure 11 shows that for a low load level, the vertical asymptote, which matches with the unstable crack propagation, was set at a higher number of cycles. With the increase of load conditions, the fatigue limit was found to be lower. Comparing the results of the different density specimens, the fatigue strength was higher for higher density structures. A like-Ashby-Gibson relationship was found between relative fatigue strength and relative density [55]. The fatigue mechanism observed from the experimental results seemed to be a combination of cyclic ratcheting and fatigue crack propagation. 

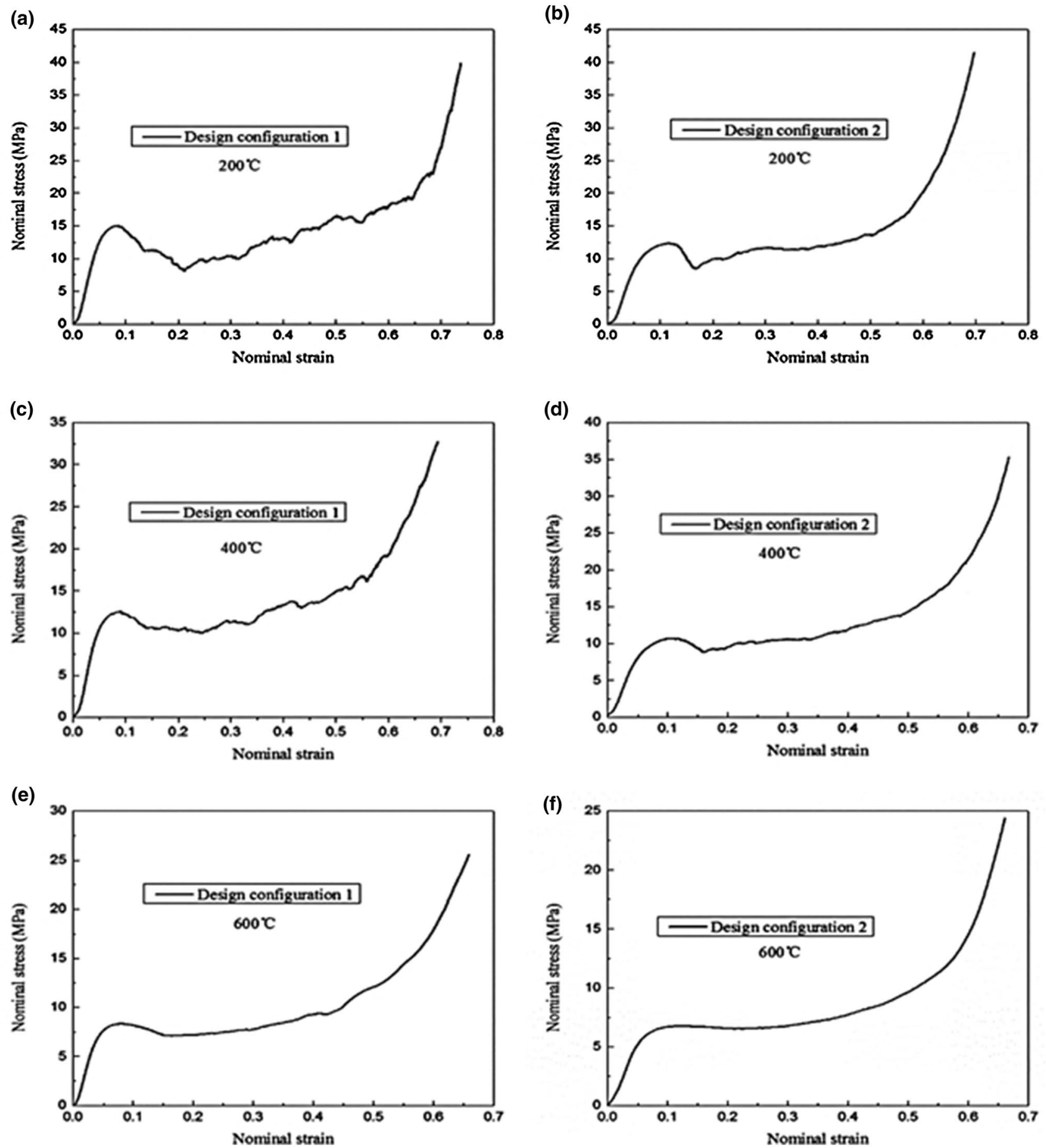

Fig. 9 Nominal stress-strain curves at different temperatures for configuration $1 \mathbf{a}, \mathbf{c}, \mathbf{e}$ and configuration 2 b, d, f [70]

Xiao et al. [86] studied the mechanical properties of open-cell rhombic dodecahedron structure at different loading rates for dynamic loading. Different sizes of both unit cell and strut were also investigated. The results showed that for low values of loading rate, the stress-strain curves respect the three-stage trends. These results were comparable to previous studies meaning that the low strain rate may be considered static [66, 70, 72]. When the loading rate increased, the typical trend of the lattice behaviour disappeared since the bulk elastic behaviour was not detected (the last part of the typical trend). The failure mode for all the structures was the same also that revealed in the previous studies with failure bands at $45^{\circ}[66,70]$. In addition to experimental test, an FE model was also developed 
Table 2 Hardness Vickers of the cell for specimens tested by Cheng et al. [66]

\begin{tabular}{llll}
\hline Samples & $\begin{array}{l}\text { Ligament (strut) } \\
\text { length }(\mathrm{mm})\end{array}$ & $\begin{array}{l}\text { Ligament (strut) } \\
\text { thickness }(\mathrm{mm})\end{array}$ & $\begin{array}{l}\text { Cell hard- } \\
\text { ness, HV } \\
(\mathrm{GPa})\end{array}$ \\
\hline Foam 1\# & $\sim 4.19$ & $\sim 1.04$ & $3.23 \pm 0.25$ \\
Foam 2\# & $\sim 3.68$ & $\sim 0.99$ & $3.30 \pm 0.10$ \\
Foam 3\# & $\sim 3.15$ & $\sim 0.84$ & $3.36 \pm 0.19$ \\
Lattice 1\# & $\sim 3.13$ & $\sim 1.08$ & $3.03 \pm 0.22$ \\
Lattice 2\# & $\sim 2.54$ & $\sim 0.94$ & $3.15 \pm 0.09$ \\
Lattice 3\# & $\sim 2.07$ & $\sim 0.86$ & $3.24 \pm 0.16$ \\
Lattice 4\# & $\sim 1.69$ & $\sim 0.77$ & $3.31 \pm 0.14$ \\
Lattice 5\# & $\sim 1.24$ & $\sim 0.72$ & $3.51 \pm 0.16$ \\
\hline
\end{tabular}

considering the actual surface quality of the struts based on $\mathrm{X}$-ray tomography [86]. The numerical results matched well with the results from mechanical tests.

\subsection{Effect of the Precision of the EBM Process and the Surface Roughness on the Mechanical Properties}

The accuracy of the EBM process is mainly affected by heat transfer [40]. Due to the high working temperature, the shrinkage of the material and the unmelted powder that could be found attached to the part can cause an error of size and dimensions [88]. Especially, for the smaller details and features, as in the case of the lattice structures, this deviation affects the final performance of the structure.

According to the study presented by van Grunsven et al. [69], the bigger deviation has been found for the smaller strut thickness when the nominal geometry (CAD model) was compared with the actual lattice produced parts by the EBM Arcam S12. This difference occurs because smaller strut sizes have a characteristic dimension of about the size of the minimum melted volume, equal to the spot of the electron beam. Thus, the replication of the CAD model with dimensions around 200-500 $\mu \mathrm{m}$ becomes less accurate with respect to the bigger geometrical features.

Horn et al. [79] evaluated the precision of the Arcam A2 system. For several specimens, a theoretical relative density from the CAD model and then after the building phase was evaluated. For each specimen was also evaluated the actual density from measured weight and volume. Respect to the calculated theoretical relative densities, the actual relative densities resulted to be dependent by the cell size. In particular, for the smaller cell sizes the deviation between the theoretical and the actual values is higher than the values for the larger cell size. Especially, the actual relative densities
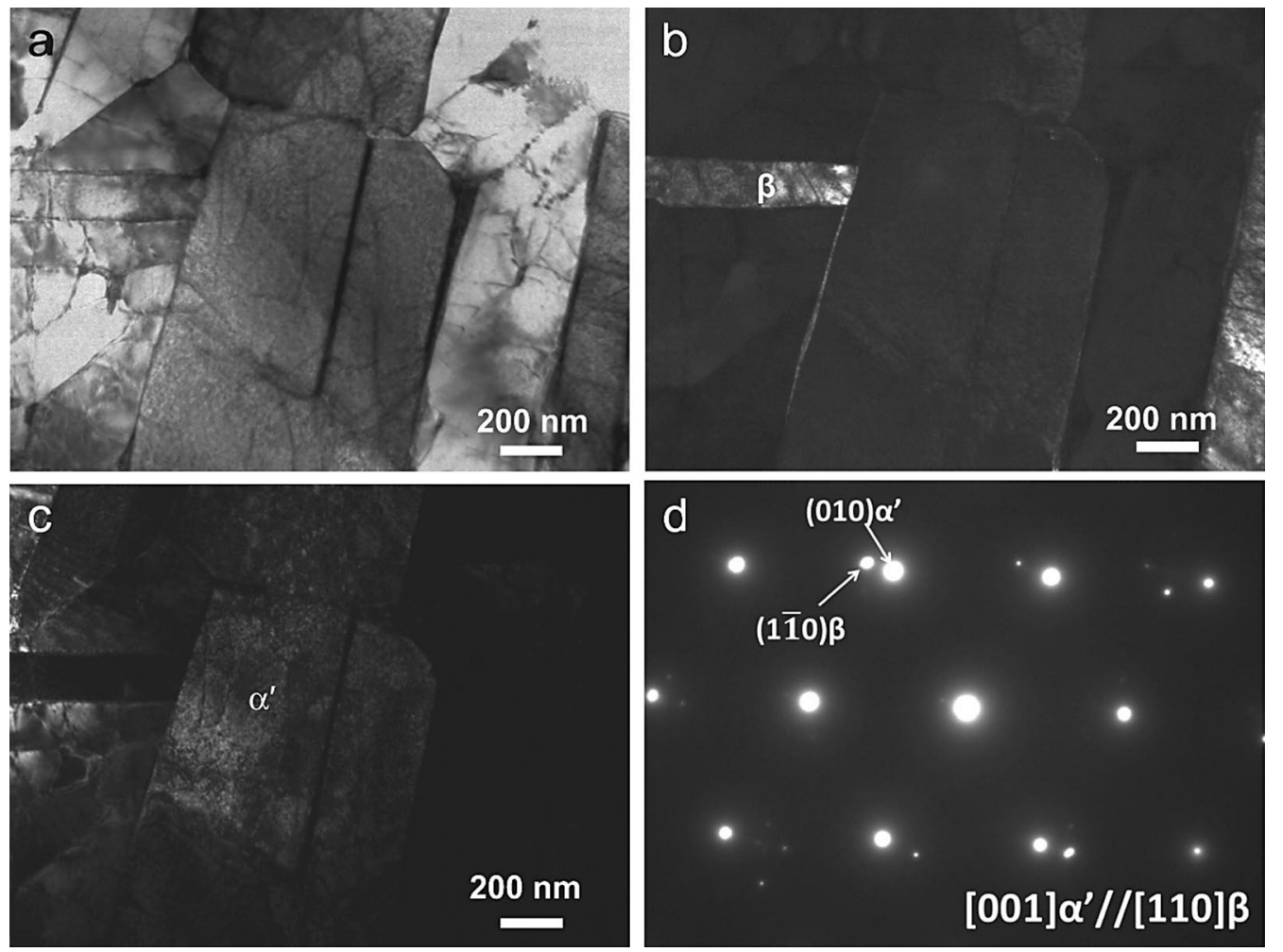

Fig. 10 TEM micrographs of the mesh sample with density of $1.68 \mathrm{~g} / \mathrm{cm}^{3}$, in which $\mathbf{a}$ is bright-field image, and $\mathbf{b}$ and $\mathbf{c}$ are dark-field images taken from the diffraction spots of the $\beta$ phase and the $\alpha$ ' martensite noted by arrows in diffraction pattern $\mathbf{d}$ [66] 


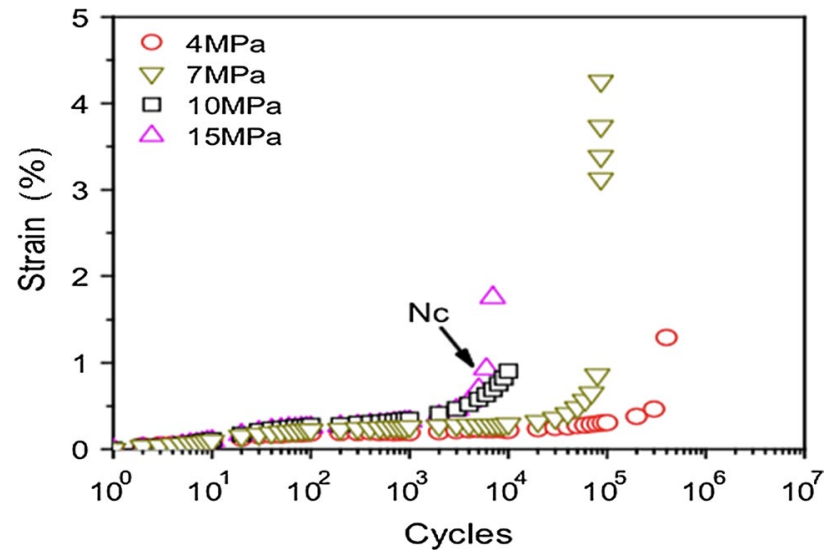

Fig. 11 A strain-cycle diagram showing the trends of strain accumulation for different load conditions [72]

for the smaller cells are not affected by the size change. This difference occurs due to the precision of the machine which is lower for the smaller strut sizes because the melt pool size is comparable with the strut size. For the Arcam A2 system, Horn et al. [79] suggested that the strut size limit is around $0.5 \mathrm{~mm}$; this value is in accordance with the previous mentioned study by van Grunsven et al. [69].

Parthasarathy et al. [67] evaluated the process precision for the building of the cubic lattice structures. Four sets of specimens were fabricated on an Arcam S12 system with differences in the pore and strut size, with an overall designed porosity ranging from 60.91 to $75.83 \%$. A low-pressure pycnometer was used to evaluate the relative density and a CT scan with an image reconstruction software to reconstruct the 3D model of the fabricated parts for evaluating the actual strut and pore sizes. For the fourth set of specimens with minimum strut size of $0.450 \mathrm{~mm}$ the porosity error between the CAD model and the fabricated model was maximum, more or less in the amount of $22 \%$, and the EBM process was more accurate with the increase of the strut size. This result occurs for the same reasons previously explained by $[69,79]$.

Sun et al. [89] studied the effect of surface roughness on the mechanical properties of Ti-6Al-4V specimens. Both chemical etching and machining were used to improve the surface corrugation height. The results of tensile tests were compared with the results of the as-built condition specimens. To investigate surface morphology, a field emission scanning electron microscope (FE-SEM) and an Alicona infinite focus microscope were used. Figure 12 depicts the different surface morphologies with both of the cited methods. The surface roughness of lattice structure was reduced with both chemical etching and machining. The $R_{\mathrm{a}}$ and $R_{\mathrm{z}}$ were, respectively, $38.9 \mu \mathrm{m}$ and $209.5 \mu \mathrm{m}$ for the as-built structure. These values for the chemical etching and the machining were $10.9 \mu \mathrm{m}$ and $58.19 \mu \mathrm{m}$ and $0.13 \mu \mathrm{m}$ and
$0.95 \mu \mathrm{m}$, respectively. As far as the tensile test is concerned, the as-built specimens showed the lowest value for both yield stress (YS) and ultimate tensile strength (UTS), while the etched and machined specimens exhibited similar results. The results can be explained considering that the as-built condition presents the highest values of surface roughness. Thus, the external corrugations cause stress concentrations, the as-built specimens reached fracture faster. On the other hand, since the difference between etching and machining is not so evident through the tensile tests, chemical etching can be considered as a good technique to enhance the mechanical properties of lattice structures.

Suard et al. [90] studied the structural characterization and the geometrical imperfection derived from the construction on the EBM system of the octet-truss lattice structure at the scale of a single strut. The roughness was measured using the images captured by X-ray tomography, and it resulted in having a period of about $50 \mu \mathrm{m}$.

Figure 13 shows images of the octet-truss; Fig. 13b and c depict the reconstruction of a single strut based on the X-ray tomography images. The surface roughness is partly due to unmelted powder stuck to the melted zone. Suard et al. [90] defined an efficient volume ratio given by the relationship:

$\varphi=\frac{V_{\text {incribedcylinder }}}{V_{\text {strut }}}$

where $V_{\text {inscribedcylinder }}$ is the volume of the inscribed cylinder inside the strut, and $V_{\text {strut }}$ is the volume of the strut itself. These two parameters were estimated from the 3D image analysis. The aim of that study was to evaluate the dependency of this volume ratio upon strut orientation and strut diameter. The first result of the study was obtained after studying $\varphi$ with respect to the CAD strut size: with the increase of the theoretical cross-section of the struts, the volume ratio had an increase that was lower with respect to the increment of the theoretical cross-section of the struts. This is justified by the fact that an almost constant roughness value was detected for all the struts analysed. The valuations of the strut orientation showed clearly that the smaller volume ratios were for the struts build parallel to the building platform, and higher volume ratios were for the struts build perpendicular to the start plate [90].

Suard et al. [57] compared the nominal CAD structures and the produced ones. They showed that the produced struts were always thinner than the nominal ones. Consequently, the manufactured relative density was lower than the designed one. Additionally, the final dimension of the strut is also affected by the orientation on the dimension of the structure.

Figure 14 shows the aspect ratio for struts which were built at $0^{\circ}, 45^{\circ}$ and $90^{\circ}$ with respect to the start plate. For struts build vertically $\left(90^{\circ}\right)$, the shape of the section was 

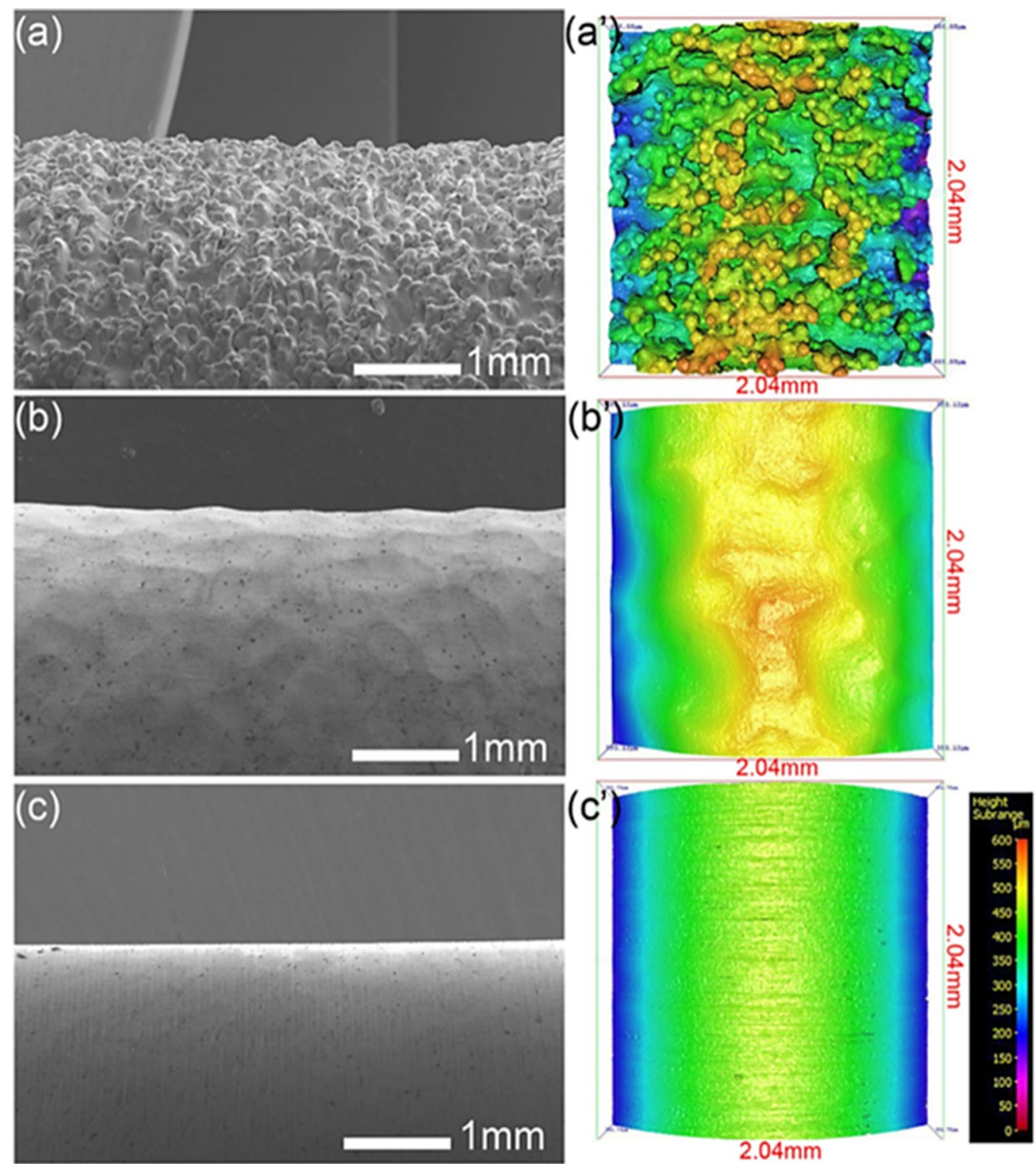

Fig. 12 FESEM surface images of as-fabricated a, surface-etched $\mathbf{b}$ and machined $\mathbf{c}$ specimens; surface conditions of as-fabricated a', surfaceetched b' and machined c' specimens observed under Alicona IFM [89]

nearly circular; instead, moving towards the horizontal strut $\left(0^{\circ}\right)$, its actual section cannot be considered circular. This phenomenon was explained by considering the heat transfer during the construction phase on the EBM system. Since the powder has a lower thermal conductivity with respect to the melted area, for the struts build at $0^{\circ}$, a heat accumulation resulted in an over-melted zone that increases the aspect ratio [57]. To consider this deviation and predict the mechanical behaviour of a lattice structure, the mechanical equivalent diameter of single struts was introduced [57]. The equivalent diameter $D_{\mathrm{EQ}}^{\mathrm{NUM}}$ was intended as the diameter that produces the elastic behaviour of a build strut calculated by a Fast Fourier Transform calculation. A geometrical equivalent cylinder diameter $D_{\mathrm{EQ}}^{\mathrm{GEOM}}$ was also defined as the diameter of the inscribed cylinder into the strut.

Table 3 resumes the findings of Surad's investigations in which it is possible to see that equivalent diameter is averagely thinner than the nominal diameter $D^{\mathrm{CAD}}$. In addition, $D_{\mathrm{EQ}}^{\mathrm{GEM}}$ is thinner than $D_{\mathrm{EQ}}^{\mathrm{NUM}}$. An FE simulation based on these data was conducted to evaluate the relative stiffness of octet-truss type lattice structures with each diameter shown in Table 3. To obtain the range of relative density, the unit cell size was adapted with a fixed strut size for each case. These results were compared with experimental results from uniaxial compressive tests conducted on the build specimens. 


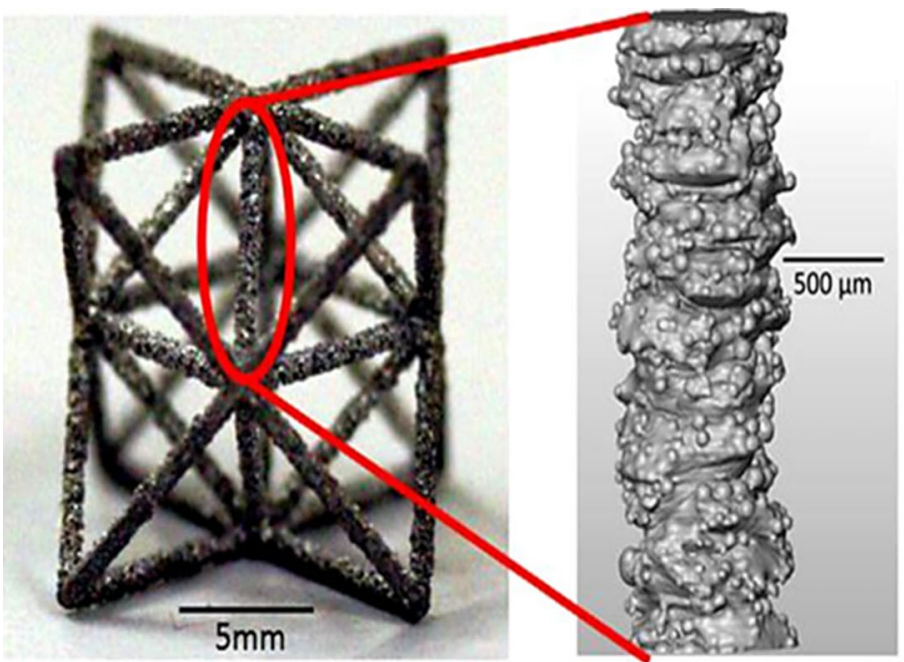

(a)

(b)

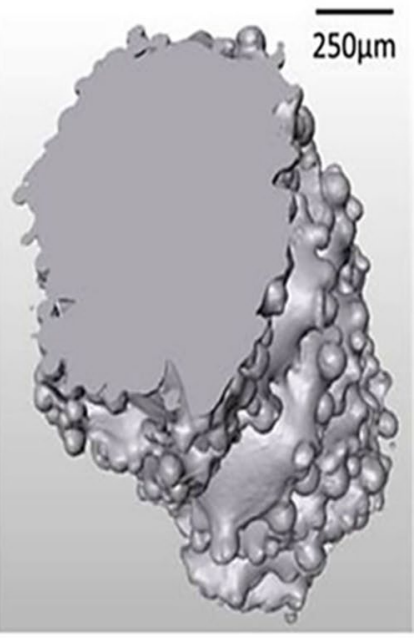

(c)

Fig. 13 Images showing a global octet-truss unit cell $\mathbf{a}$, a 3D reconstruction of one strut $\mathbf{b}$ an isometric view of a $1 \mathrm{~mm}$ strut $\mathbf{c}$ [90]

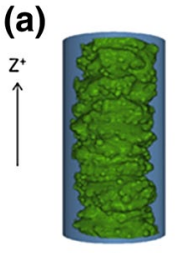

(i)

(b)

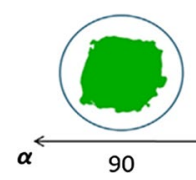

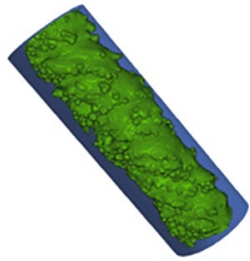

(ii)

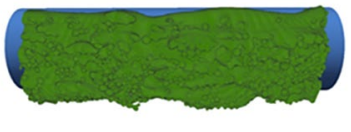

(iii)

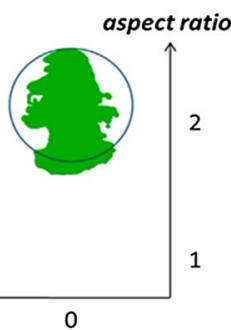

Fig. 14 a Comparison between the CAD design (in blue) and the build struts (in green) at different construction angles; b aspect ratio with respect to construction angle [57]

Table 3 Equivalent diameters according to CAD, numerical and geometrical evaluations with respect to strut's construction angle [57]

\begin{tabular}{llll}
\hline & $\alpha$ & & \\
\cline { 2 - 4 } & $90^{\circ}$ & $45^{\circ}$ & $0^{\circ}$ \\
\hline$D^{\mathrm{CAD}}(\mathrm{mm})$ & 1 & 1 & 1 \\
$D_{\mathrm{EQ}}^{\mathrm{NUM}}(\mathrm{mm})$ & 0.576 & 0.581 & 0.706 \\
$D_{\mathrm{EQ}}^{\mathrm{GEOM}}(\mathrm{mm})$ & 0.456 & 0.414 & 0.518 \\
\hline
\end{tabular}

Figure 15 collects the trends of FEM and experimental results. FEM simulations with the nominal diameter of the struts of $1 \mathrm{~mm}$ overestimated the experimental trend.

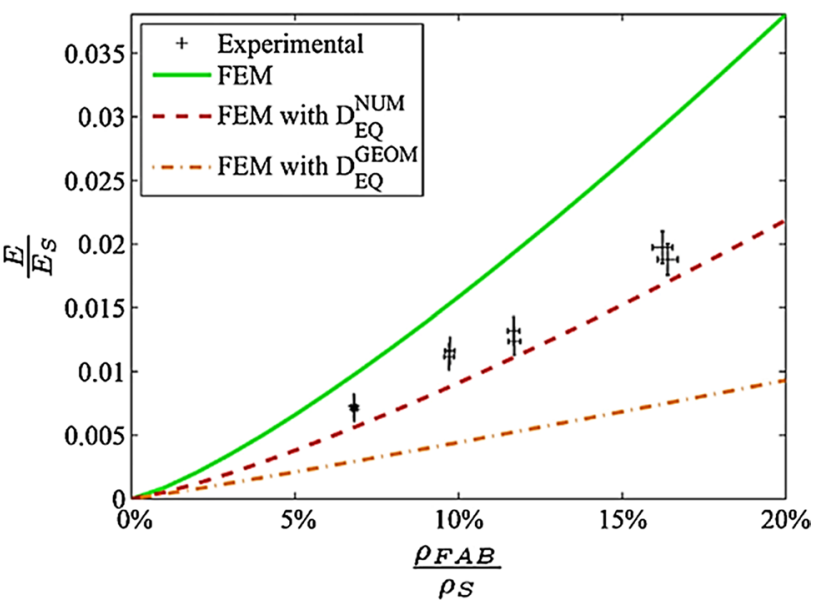

Fig. 15 Relative elastic modulus with respect to relative density for different strut sizes: green curve for $D^{\mathrm{CAD}}$, the red dashed curve for $D_{\mathrm{EQ}}^{\mathrm{NUM}}$, the orange curve for $D_{\mathrm{EQ}}^{\mathrm{GEO}}$. Experimental results are depicted in black [57]

FEM simulations conducted with both equivalent diameters underestimated experimental results, but the calculated curve with the numerical approach was similar to the experimental data.

Yang [85] developed an experimental-assisted design for octahedral lattice structures in which the unit cell was analytically modelled and analysed through FE analysis. For the validation, the structure was produced by an Arcam S400 system. After the modelling phase, uniaxial compression was simulated by FE analysis to detect the effects of both the number of layers in the z-direction and the number of unit cells in the $X Y$ plane. The modelling successfully represented the Young's modulus prediction for the octahedral 
lattice structures. Additionally, the chosen cell exhibited a good predictable size effect. The elastic modulus increases with the increase of both the number of layers and the unit cells in the $X Y$ plane. This result is in good accordance with the previously analysed study by Horn et al. [79].

Differently from the previous analysed studies which focus on just the cellular specimens made by EBM, Chang et al. [91] investigated the differences between two different metal AM techniques. They, indeed, studied the specific effect of surface roughness on the fatigue properties of dental implants made with both L-PBF and EBM parts made of Ti-6Al-4V ELI. The surface of as-built EBM specimens was rougher than the surface of as-built SLM. Consequently, in fatigue behaviour, it was possible to see that L-PBF made specimens exhibit longer fatigue life with respect to the other analysed conditions. The EBM made specimens had instead the worst values of fatigue life, even lower than the cast samples. This result occurred because in fatigue behaviour the roughness of the surface plays an essential role in fatigue life. Since $R_{a}$ increases moving from L-PBF, cast and EBM cases, it was possible to conclude that fatigue life of Ti-6Al-4V ELI decreases with the increase of the surface roughness.

Focusing only on one AM technique, Epasto et al. [84] studied the effect of surface roughness on the mechanical performance of the Ti-6Al-4V bulk specimens made by EBM. To investigate this particular effect, some of the fabricated specimens were machined. The average surface roughness was equal to $21.94 \mu \mathrm{m}$ and $0.78 \mu \mathrm{m}$ for the as-built and machined specimens, respectively. After the conduction of tensile tests, the stress-strain trends were computed, and the results are shown in the table below.

As it is possible to see from Table 4, the main difference is the higher value of the elongation at failure for machined samples. This result occured because the surface roughness of the machined sample, as mentioned earlier, has a lower value with respect to the as-built specimen.

Table 4 Results of tensile tests for both as-built and machined conditions from the study by Epasto et al. [84]

\begin{tabular}{lllll}
\hline Specimen & $\begin{array}{l}\text { Yield } \\
\text { stress } \\
(\mathrm{MPa})\end{array}$ & $\begin{array}{l}\text { Tensile } \\
\text { strength } \\
(\mathrm{MPa})\end{array}$ & $\begin{array}{l}\text { Young's } \\
\text { modulus } \\
(\mathrm{GPa})\end{array}$ & $\begin{array}{l}\text { Elongation } \\
\text { at failure } \\
(\%)\end{array}$ \\
\hline As-built & 885 & 895 & 118 & 5.4 \\
Machined & 873 & 965 & 108 & 17.5 \\
\hline
\end{tabular}

\section{Effects of Thermal Treatments on the Mechanical Behaviour of Ti-6Al-4V Alloy Made by EBM}

Heat treatments on EBM made parts are mainly conducted to reduce internal porosity and achieve a fully dense material. Since the porosity could appear due to the presence of porosity inside the powder itself, Cunningham et al. [50] measured the powder porosity to correlate the subsequent results on the treated parts. Two batches of powder were analysed. Both powder batches showed a certain quantity of porosity that was maintained after the EBM process into the as-built specimens. To reduce the internal porosity, a HIP treatment was performed for $2 \mathrm{~h}$, at $900{ }^{\circ} \mathrm{C}$ in an Argon pressure of $103 \mathrm{MPa}$, according to ASTM F2924 [92]. After the HIP treatment, the porosity was erased from one type of powder. Instead, there was a little number of pores in the other type. A solutionizing treatment was then carried out to evaluate the pore regrowth. The solutionized sample with a residual porosity after the HIP treatment showed a significant pore regrowth, while no porosity was detected in the other sample.

Tammas-Williams et al. [51] studied the effectiveness of HIP on the EBM samples produce by an Arcam S12 system. The samples were HIPed for $2 \mathrm{~h}$ at $920^{\circ} \mathrm{C}$ with a pressure of $100 \mathrm{MPa}$ of Argon and a cooling rate of $6{ }^{\circ} \mathrm{C} /$ $\min$.

Figure 16 shows the comparisons between the treated and untreated samples. After the HIP treatment (Fig. 16b), all the porosities were removed from the samples labelled $\mathrm{C} 1$ and MC, while for the sample labelled T3 tunnel defects connected to the surface were still visible. In general, HIP treatment showed a great potential to be used as a post processing process to reduce the porosity content up to $60 \%$ [51]. The following work of the same authors evaluated the porosity regrowth during the post-treatments [93]. The specimens were HIPed in the same conditions of the previous study [56], and then, three different annealing conditions were tested. In the first condition (HT1), a total time of $10 \mathrm{~min}$ at $1035{ }^{\circ} \mathrm{C}$ under vacuum were assumed. On the other hand, in the second condition (HT2) total time of $10 \mathrm{~h}$ at the same temperature and pressure conditions of the previous treatment was fixed to evaluate the pores regrowth. Lastly, in the third condition (HT3) total time of $10 \mathrm{~min}$ in vacuum conditions at $1200{ }^{\circ} \mathrm{C}$ was set to evaluate the temperature effect on pore regrowth.

Table 5 shows the results of the CT scan analysis. After the HIP treatment, no porosity was detected at the scanner resolution of $5.2 \mu \mathrm{m}$. After the HT1, a certain number of pore with a certain mean equivalent diameter was detected. The number of pores increases after the HT2 and HT3. However, the volume fraction of pores was always lower 
(a)

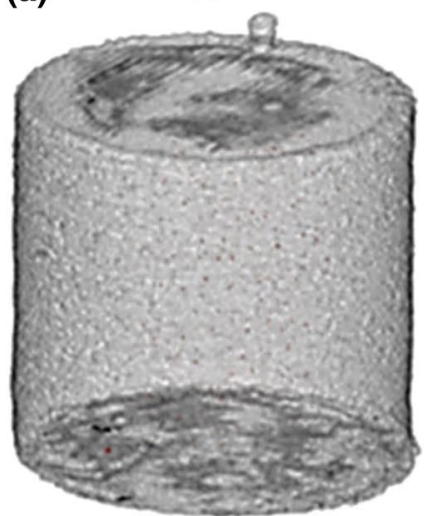

(b)

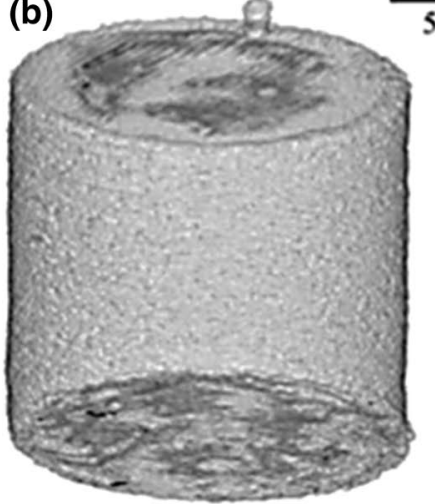

$\mathrm{T} 3$

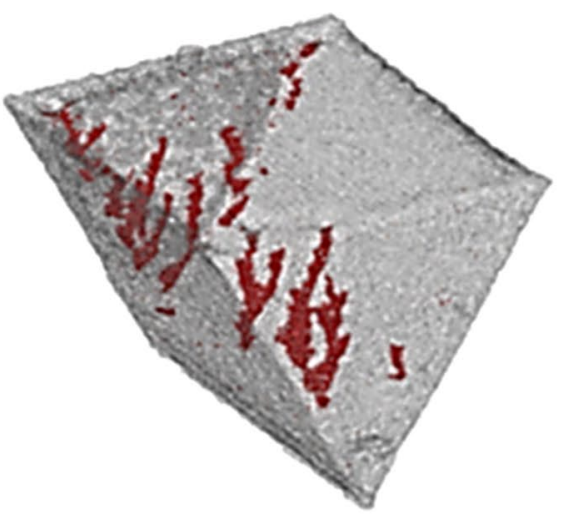

$5 \mathrm{~mm}$

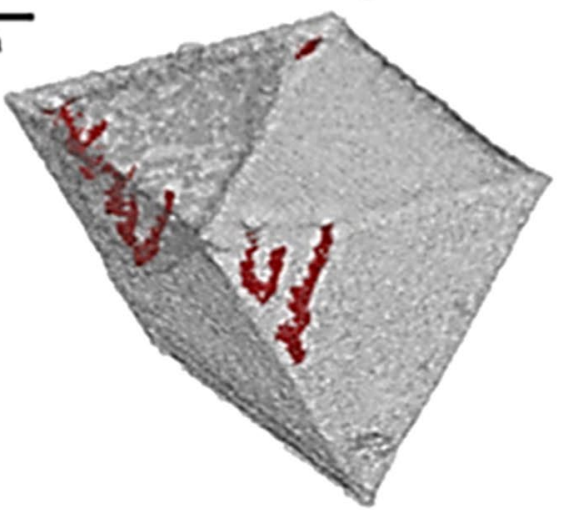

$\mathrm{MC}$
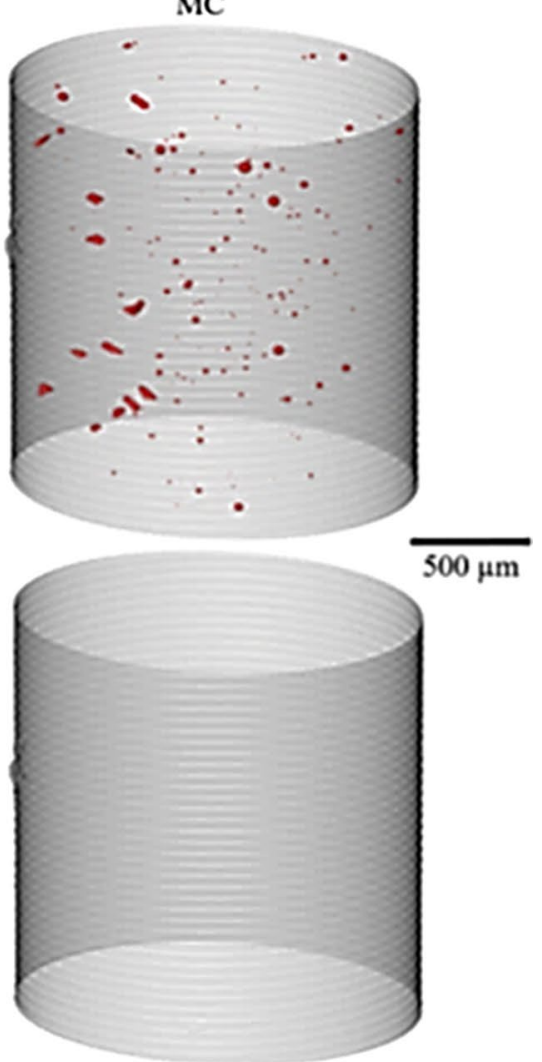

Fig. 16 Computed tomography (CT) images showing porosity in red; a as-built condition, $\mathbf{b}$ after HIP conditions [51]

Table 5 Statistical data from the same sample in the five different conditions analysed [93]

\begin{tabular}{llrll}
\hline Condition & $\begin{array}{l}\text { Volume frac- } \\
\text { tion }(\%)\end{array}$ & $\begin{array}{l}\text { Number of } \\
\text { pores }\end{array}$ & $\begin{array}{l}\text { Mean equiv. } \\
\text { dia. }(\mu \mathrm{m})\end{array}$ & $\begin{array}{l}\text { Max. } \\
\text { equiv. dia. } \\
(\mu \mathrm{m})\end{array}$ \\
\hline As-built & 0.0397 & 309 & 13.3 & 53.3 \\
HIPed & 0.0000 & 0 & - & - \\
HT1 & 0.0007 & 49 & 8.4 & 18.6 \\
HT2 & 0.0011 & 63 & 9.2 & 20.0 \\
HT3 & 0.0026 & 140 & 9.4 & 21.6 \\
\hline
\end{tabular}

than the one in the as-built conditions. Comparing HT2 and HT3 results, it is possible to understand that the temperature effect is more significant on pore regrowth than the time effect.

The effects of heat treatments on the mechanical response of Ti-6Al-4V parts made by EBM were investigated also by de Formanoir et al. [94]. In their study, two kinds of heat treatments were evaluated: the first set of them was conducted below the $\beta$-transus temperature, at $950{ }^{\circ} \mathrm{C}$ for $60 \mathrm{~min}$, while the second one was conducted over the characteristic temperature, at $1040{ }^{\circ} \mathrm{C}$ for $30 \mathrm{~min}$. In addition, in each set of the cited heat treatments, the cooling rate was changed between AC (air cooling) and FC (furnace cooling), in order to understand the effects inducted by the different cooling rates. The results showed that the microstructure of the heat-treated samples under $\beta$-transus did not change markedly, resulting just in a slightly coarsening. On the other hand, the over $\beta$-transus heat treatments changed completely the microstructure. This occurred because the diffusion at temperatures above $\beta$-transus permitted a completely renewing of the microstructure, which stabilized in a much coarse way with also a different orientation of the $\alpha$ and $\beta$ phases.

As far as the effects of heat treatments on the mechanical behaviour of Ti-6Al-4V lattice structures made by EBM is concerned, only a few works have been found in the literature that addressed this topic. Epasto et al. [84] studied the effect of thermal treatments on the compressive behaviour with the aim to investigate whenever there is an effect of residual stresses on EBM components. Thus, stress relief was performed on some specimens which were heated up to $300{ }^{\circ} \mathrm{C}$; this temperature was maintained for $3 \mathrm{~h}$, and then, the specimens were cooled down in the furnace. At this point, compression tests were conducted, and, after the evaluation of the stress-strain trends, it was possible to see that the heat-treated samples showed values of UCS and Young's modulus slightly lower. Thus, it was 
concluded that the possible presence of residual stresses does not significantly affect the compressive behaviour of the lattice structure. The effect of defects on the mechanical response of Ti-6Al-4V cubic lattice structure produced by EBM was analysed by Hernandez-Nava et al. studies [48]. Compression and hardness tests were carried out. Two annealing treatments were run at a lower than $\beta$-transus $\left(960^{\circ} \mathrm{C}\right)$ and a higher than $\beta$-transus $\left(1200^{\circ} \mathrm{C}\right)$, respectively. Both of them were conducted for a total time of $120 \mathrm{~min}$ and air pressure of $0.1 \mathrm{MPa}$. For the as-built condition, the microstructure of the struts perpendicular to the start plate showed a combination of $\alpha$ and $\beta$ phases, according to previous studies on the bulk material [33, 47, 73]. Figure 17 shows the differences between three different points. Diffusionless $\alpha$ ' martensite for regions closer to the construction plate was noticed. For the under $\beta$-transus annealing, no consistent differences were found with respect to the as-built microstructure. For the over $\beta$-transus annealing instead, a coarsening of the microstructure was detected. As a consequence, the mechanical tests showed lower compressive yield stress by approximately $11 \%$.

Table 6 collects all the data regarding the parameters of the thermic cycles, showing also the target of each heat treatment.
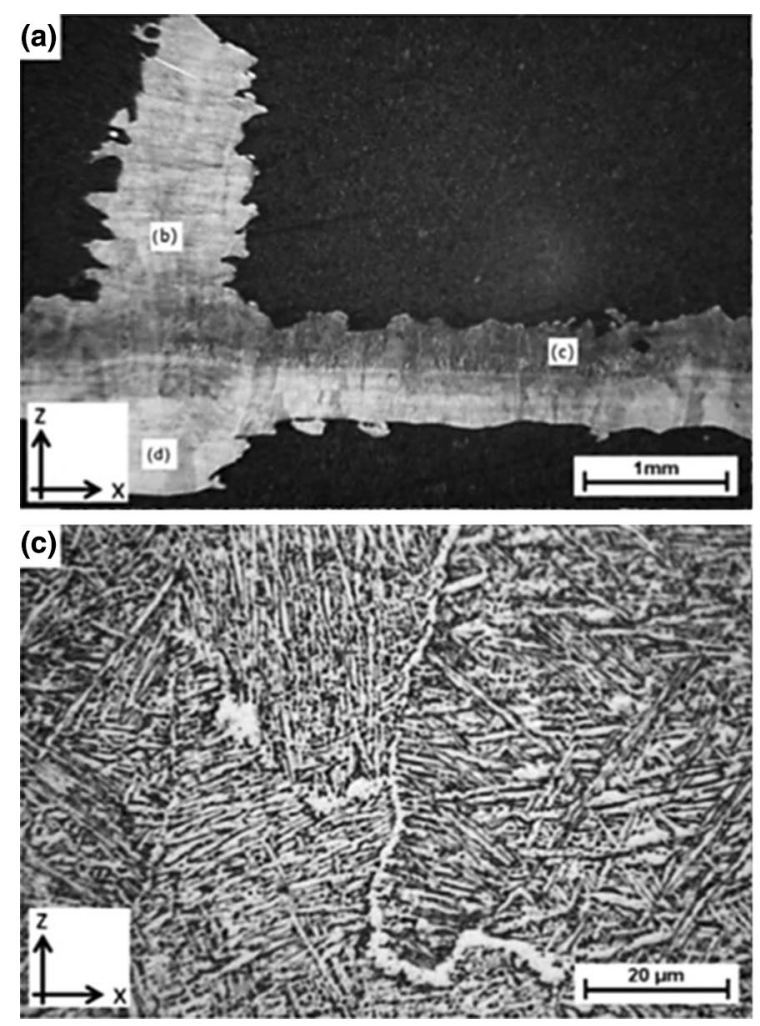

\section{Conclusions}

In this paper, the studies carried out on the properties of Ti-6Al-4V lattice structures made by electron beam melting (EBM) were reviewed. According to this comprehensive review, the following conclusion can be drawn:

(1) The AM processes, especially EBM, are an excellent technique to fabricate complex structure that cannot be made with other manufacturing processes. Especially, for the fabrication of Ti-6Al-4V parts, EBM process reduces the possibility that defects are presented in HDI and LDI;

(2) The microstructure of as-built Ti-6Al-4V parts made by EBM is mainly influenced by the thermal cycle of the EBM process itself. The microstructure consists of a coarse mixture of $\alpha$ and $\beta$ for the bulk material. For the cellular materials, a finer microstructure with the presence of the metastable phase $\alpha^{\prime}$ was noticed because of the higher cooling rate.

(3) The relative density is the main descriptor that is used in literature for the geometry of the lattice structure.

(4) Despite all the attempts to numerically simulate the behaviour of the lattice structure, in the literature, the mechanical response of $\mathrm{Ti}-6 \mathrm{Al}-4 \mathrm{~V}$ cellular materials is investigated experimentally.
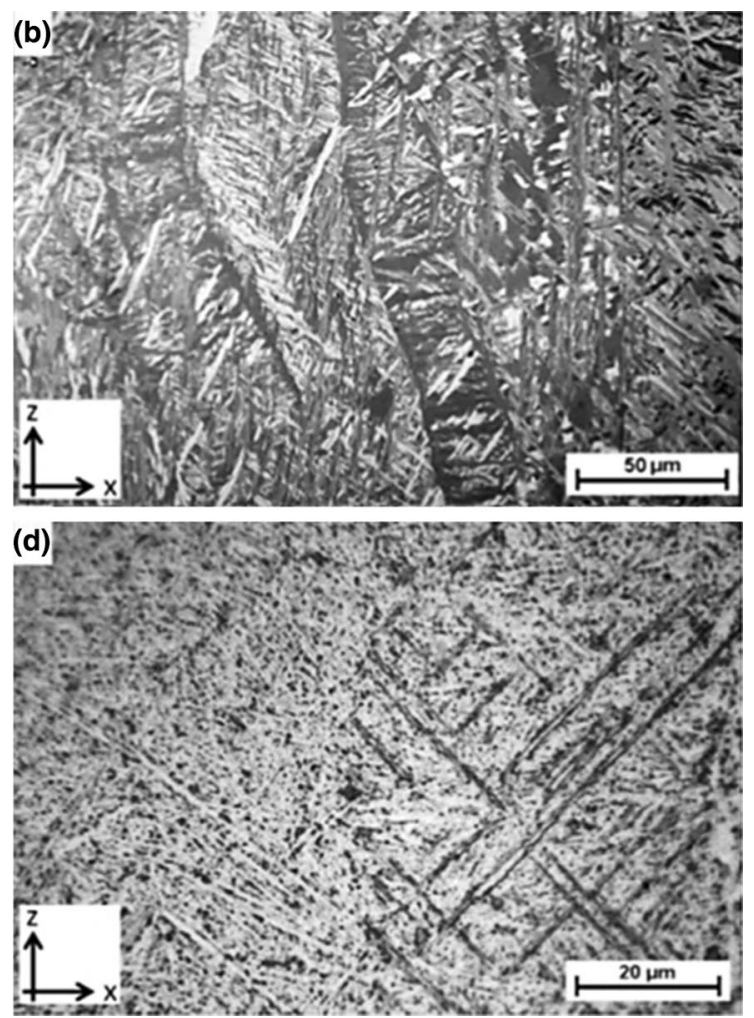

Fig. 17 Optical micrographs of as-built condition $\mathbf{a}$ with three different locations of interest $\mathbf{b}, \mathbf{c}, \mathbf{d}$ [48] 


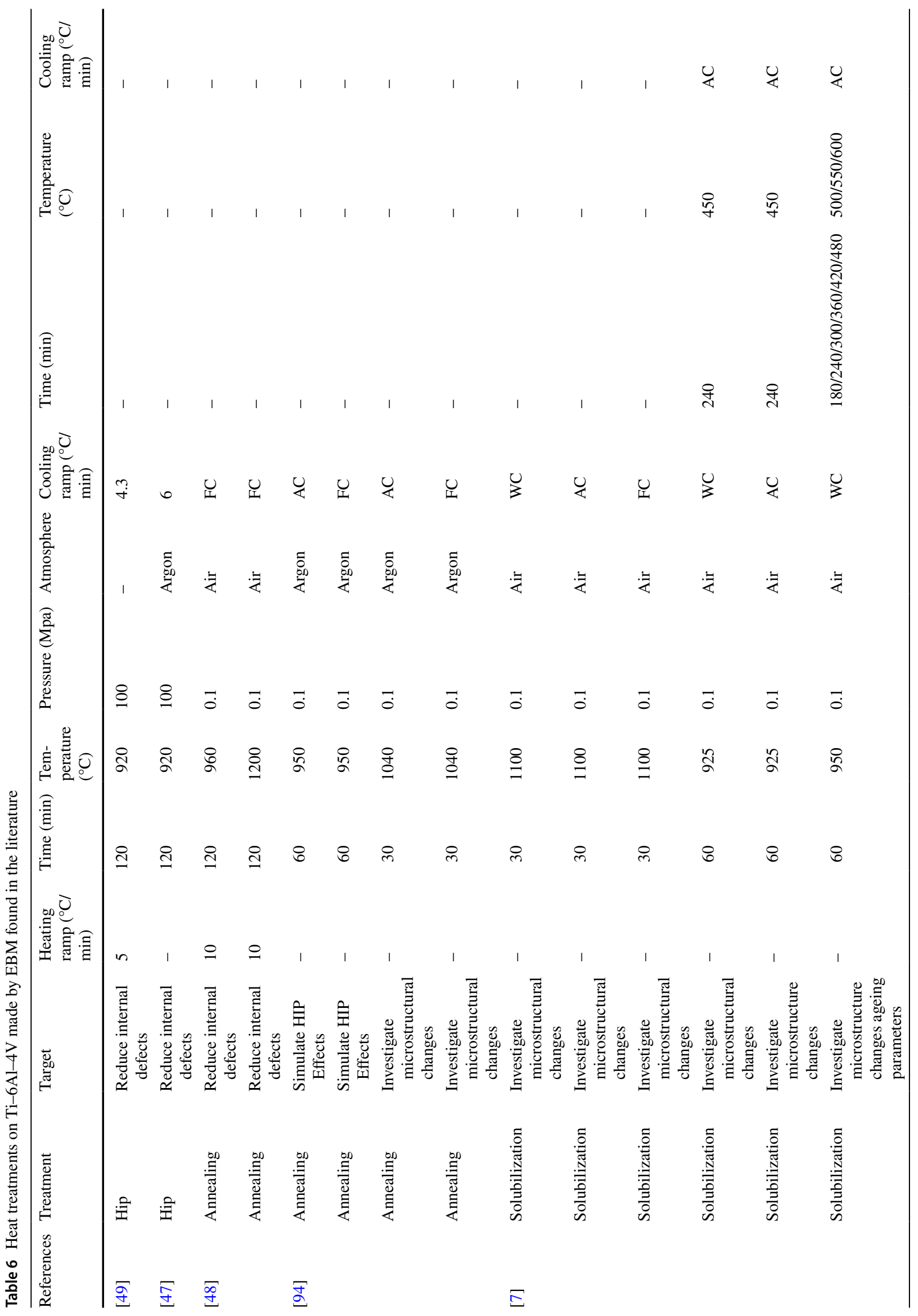




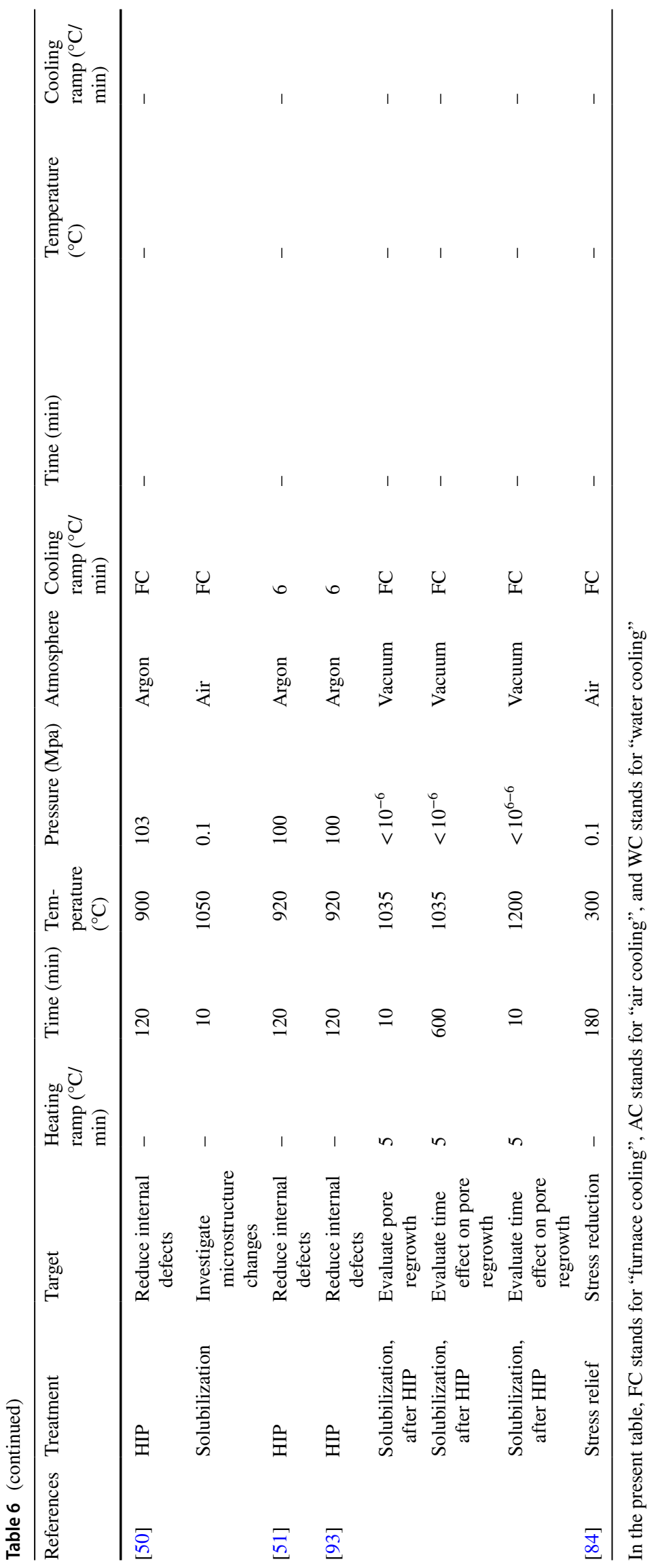


(5) The empirical models tend always to obtain a like the Ashby and Gibson relationship for which $\mathrm{E}$ and the UCS of the analysed cellular material depend only by its relative density.

(6) The failure under compressive behaviour occurs due to brittle fracture, with crush bands at $45^{\circ}$.

(7) A higher working temperature produces a softening of mechanical behaviour and a change in the failure angle. The crush bands do not occur indeed at $45^{\circ}$, but at a random angle;

(8) The surface roughness plays one of the most important roles in the mechanical response of lattice structures. Lower values of both $R_{\mathrm{a}}$ and $R_{\mathrm{z}}$ improve the mechanical properties, especially the fatigue behaviour. For the static compressive behaviour, the corrugations represent stress concentration points while for the fatigue they lead to failure in a lower number of cycles.

(9) The effects of the heat treatments on the bulk material have been largely analysed. On the other hand, the effects of the heat treatments on lattice structures have not been discussed thoroughly in the literature.

(10) Today, the industrial application of the lattice structure for EBM has been investigated for the medical sector in which the high biocompatibility has been exploited, and the resistance standard is less strict than the other sector.

All in all, it can be concluded that the presented review highlighted that there are still a lot of work and research to be accomplished before lattice structure can become an effective structure to be used for structural applications such as automotive and aerospace. In fact, several aspects appear still needed to be investigated. Among the reviewed papers, the main conclusion appeared that the mechanical behaviour of lattice structures is influenced by the cell shape, which slightly affects the value of the constants $C_{1}$ and $C_{5}$, and mainly by the relative density. Structures with the same relative density have indeed similar mechanical behaviour. Therefore, for instance, the effective resistance section has been never considered for the extrapolation of the equivalent Young's modulus. Additionally, a deep lack of knowledge on the mechanical behaviour on the heattreated lattice has been detected. However, today most of metal AM parts are heat-treated either to reduce the residual porosity or to tailor the microstructure. To date, therefore it is evident that no advanced application can be designed because of the lack of detailed analysis on the effect of the most common heat treatments on the lattice performance.

\section{References}

[1] I. Polmear, D. StJohn, J.F. Nie, M. Qian, Light Alloys: Metallurgy of the Light Metals (Butterworth-Heinemann, Oxford, 2017)

[2] A. Saboori, D. Gallo, S. Biamino, P. Fino, M. Lombardi, Appl. Sci. 7(9), 883 (2017)

[3] M. Peters, Titanium and Titanium Alloys (Wiley, New York, 2003)

[4] E. Brandl, A. Schoberth, C. Leyens, Mater. Sci. Eng. A 532, 295 (2012)

[5] H.M. Wang, S.Q. Zhang, X.M. Wang, Chin. J. Lasers 36, 3204 (2009)

[6] F.G. Arcella, F.H. Froes, JOM 52, 28 (2000)

[7] H. Galarraga, R.J. Warren, D.A. Lados, R.R. Dehoff, M.M. Kirka, P. Nandwana, Mater. Sci. Eng. A 685, 417 (2017)

[8] A. Mitchell, Mater. Sci. Eng. A 243, 257 (1998)

[9] W.E. Frazier, J. Mater. Eng. Perform. 23, 1917 (2014)

[10] B. Baufeld, O. Van der Biest, R. Gault, Mater. Des. 31, S106 (2010)

[11] B. Dutta, F.H.S. Froes, Met. Powder Rep. 72, 1 (2017)

[12] ASTM F2792-12a, Standard Terminology for Additive Manufacturing Technologies, F42.19, Ed. (ASTM International, West Conshohocken). https://doi.org/10.1520/F2792-12A

[13] A. Heidarzadeh, H. Pouraliakbar, S. Mahdavi, M.R. Jandaghi, Ceram. Int. 44, 3128 (2018)

[14] I. Gibson, D.W. Rosen, B. Stucker, Additive Manufacturing Technologies (Springer, New York, 2010)

[15] B. Onuike, A. Bandyopadhyay, Mater. Lett. 252, 256 (2019)

[16] L. Hitzler, M. Merkel, W. Hall, A. Öchsner, Adv. Eng. Mater. 20, 1700658 (2018)

[17] S.L. Sing, W.Y. Yeong, F.E. Wiria, J. Alloy. Compd. 660, 461 (2016)

[18] Q. Jia, D. Gu, J. Alloys Compd. 585, 713 (2014)

[19] Y. Kuo, A. Kamigaichi, K. Kakehi, Metall. Mater. Trans. A 49, 3831 (2018)

[20] A. Saboori, F. Bosio, E. Librera, M. De Chirico, S. Biamino, M. Lombardi, P. Fino, in Euro PM2018 Congr. Exhebition (Bilbao, Spain, 2018), pp. 1-6

[21] F. Bosio, A. Saboori, A. Lacagnina, E. Librera, M. De Chirico, S. Biamino, P. Fino, M. Lombardi, in Euro PM2018 Congr. Exhebition (Bilbao, Spain, 2018), pp. 1-6

[22] A. Saboori, A. Aversa, F. Bosio, E. Bassini, E. Librera, M. De Chirico, S. Biamino, D. Ugues, P. Fino, M. Lombardi, Mater. Sci. Eng. A 766, 138360 (2019)

[23] A. Saboori, A. Aversa, G. Marchese, S. Biamino, M. Lombardi, P. Fino, Appl. Sci. 9, 3316 (2019)

[24] G. Marchese, S. Parizia, M. Rashidi, A. Saboori, D. Manfredi, D. Ugues, M. Lombardi, E. Hryha, S. Biamino, Mater. Sci. Eng. A 769, 138500 (2020)

[25] T.T. Wohlers, Wohlers Report 2006: Rapid Prototyping \& Manufacturing State of the Industry: Annual Worldwide Progress Report (Wohlers Associates, Fort Collins, 2006)

[26] C. Marie, Rapid Prototyp. J. 19, 365 (2013)

[27] A.Y. Albagachiev, A.S. Krasko, N.S. Baranova, E.S. Stramtsova, A.A. Mokanu, Russ. Eng. Res. 38, 687 (2018)

[28] S. Biamino, A. Penna, U. Ackelid, S. Sabbadini, O. Tassa, P. Fino, M. Pavese, P. Gennaro, C. Badini, Intermetallics 19, 776 (2011)

[29] A. Ataee, Y. Li, D. Fraser, G. Song, C. Wen, Mater. Des. 137, 345 (2018)

[30] M. Terner, S. Biamino, P. Epicoco, A. Penna, O. Hedin, S. Sabbadini, P. Fino, M. Pavese, U. Ackelid, P. Gennaro, F. Pelissero, C. Badini, Steel Res. Int. 83, 943 (2012)

[31] Y. Zhong, L.E. Rännar, L. Liu, A. Koptyug, S. Wikman, J. Olsen, D. Cui, Z. Shen, J. Nucl. Mater. 486, 234 (2017)

[32] D. Cormier, O. Harrysson, H. West, Rapid Prototyp. J. 10, 35 (2004) 
[33] Y. Zhai, H. Galarraga, D.A. Lados, Proc. Eng. 114, 658 (2015)

[34] G. Baudana, S. Biamino, D. Ugues, M. Lombardi, P. Fino, M. Pavese, C. Badini, Met. Powder Rep. 71, 193 (2016)

[35] K. Kyzioł, Ł. Kaczmarek, G. Brzezinka, A. Kyzioł, Chem. Eng. J. 240, 516-526 (2014)

[36] M. Larsson, U. Lindhe, O. Harrysson, in Annual International Solid Freeform Fabrication Symposium (2003), p. 438

[37] S. Price, J. Lydon, K. Cooper, K. Chou, in Proceedings of the ASME 2014 International Mechanical Engineering Congress and Exposition. Volume 2A: Advanced Manufacturing, Montreal, Quebec, Canada, 14-20 November 2014. V02AT02A002 (ASME)

[38] C. Körner, E. Attar, P. Heinl, J. Mater. Process. Technol. 211, 978 (2011)

[39] J. Milberg, M. Sigl, Prod. Eng. 2, 117 (2008)

[40] M. Galati, L. Iuliano, Addit. Manuf. 19, 1-20 (2018)

[41] E. Attar, Simul. Sel. Electron Beam Melt. Process. 211, 978 (2011)

[42] A. Safdar, L.Y. Wei, A. Snis, Z. Lai, Mater. Charact. 65, 8 (2012)

[43] W. He, W. Jia, H. Liu, H. Tang, X. Kang, Y. Huang, X. Jinshu, X. Jinshu, Xiyou Jinshu Cailiao Yu Gongcheng/Rare Met. Mater. Eng. 40, 2072 (2011)

[44] T. R. Mahale, Electron beam melting of advanced materials and structures, mass customization, mass personalization. $\mathrm{PhD}$ dissertation, Industrial Engineering, Raleigh, 2009

[45] S.M. Gaytan, L.E. Murr, F. Medina, E. Martinez, M.I. Lopez, R.B. Wicker, Mater. Technol. 24, 180 (2009)

[46] P. Heinl, A. Rottmair, C. Körner, R.F. Singer, Adv. Eng. Mater. 9, 360 (2007)

[47] H.R.V. Popov, A. Katz-Demyanetz, A. Garkun, G. Muller, E. Strokin, V. Popov, A. Katz-Demyanetz, A. Garkun, G. Muller, E. Strokin, H. Rosenson, Proc. Manuf. 21, 125-132 (2018)

[48] E. Hernández-Nava, C.J. Smith, F. Derguti, S. Tammas-Williams, F. Léonard, P.J. Withers, I. Todd, R. Goodall, Acta Mater. 108, 279 (2016)

[49] T. Persenot, G. Martin, R. Dendievel, J.Y. Buffiére, E. Maire, Mater. Charact. 143, 82 (2018)

[50] R. Cunningham, A. Nicolas, J. Madsen, E. Fodran, E. Anagnostou, M.D. Sangid, A.D. Rollett, Mater. Res. Lett. 5, 516 (2017)

[51] S. Tammas-Williams, P.J. Withers, I. Todd, P.B. Prangnell, Metall. Mater. Trans. A 47, 1939 (2016)

[52] A. Khorasani, I. Gibson, M. Goldberg, G. Littlefair, Rapid Prototyp. J. 23, 295 (2017)

[53] A. Saboori, S. Tusacciu, M. Busatto, M. Lai, S. Biamino, P. Fino, M. Lombardi, J. Vis. Exp. 2018, e56966 (2018)

[54] L.E. Murr, S.A. Quinones, S.M. Gaytan, M.I. Lopez, A. Rodela, E.Y. Martinez, D.H. Hernandez, E. Martinez, F. Medina, R.B. Wicker, J. Mech. Behav. Biomed. Mater. 2, 20 (2009)

[55] L.J. Gibson, M.F. Ashby, Cellular Solids: Structure and Properties (Cambridge University Press, Cambridge, 1999)

[56] N.A. Fleck, V.S. Deshpande, M.F. Ashby, Proc. R. Soc. Math. A Phys. Eng. Sci. 466, 2495 (2010)

[57] M. Suard, G. Martin, P. Lhuissier, R. Dendievel, F. Vignat, J.J. Blandin, F. Villeneuve, Addit. Manuf. 8, 124 (2015)

[58] K.J. Maloney, K.D. Fink, T.A. Schaedler, J.A. Kolodziejska, A.J. Jacobsen, C.S. Roper, Int. J. Heat Mass Transf. 55, 2486 (2012)

[59] A.G. Evans, J.W. Hutchinson, M.F. Ashby, Prog. Mater Sci. 43, $171(1998)$

[60] G.W. Kooistra, V.S. Deshpande, H.N.G. Wadley, Acta Mater. 52, 4229 (2004)

[61] L.E. Murr, S.M. Gaytan, F. Medina, H. Lopez, E. Martinez, B.I. Machado, D.H. Hernandez, L. Martinez, M.I. Lopez, R.B. Wicker, J. Bracke, Philos. Trans. R. Soc. A Math. Phys. Eng. Sci. 368, 1999 (2010)
[62] M. Niinomi, Metall. Mater. Trans. A 33, 477 (2002)

[63] J.W. Park, H.K. Kim, Y.J. Kim, J.H. Jang, H. Song, T. Hanawa, Acta Biomater. 6, 2843 (2010)

[64] F. Calignano, M. Galati, L. Iuliano, P. Minetola, J. Healthc. Eng. 2019, 9748212 (2019)

[65] P. Heinl, L. Müller, C. Körner, R.F. Singer, F.A. Müller, Acta Biomater. 4, 1536 (2008)

[66] X.Y. Cheng, S.J. Li, L.E. Murr, Z.B. Zhang, Y.L. Hao, R. Yang, F. Medina, R.B. Wicker, J. Mech. Behav. Biomed. Mater. 16, 153 (2012)

[67] J. Parthasarathy, B. Starly, S. Raman, A. Christensen, J. Mech. Behav. Biomed. Mater. 3, 249 (2010)

[68] O. Cansizoglu, O. Harrysson, D. Cormier, H. West, T. Mahale, Mater. Sci. Eng. A 492, 468 (2008)

[69] W. van Grunsven, E. Hernandez-Nava, G. Reilly, R. Goodall, Metals (Basel) 4, 401 (2014)

[70] L. Xiao, W. Song, C. Wang, H. Liu, H. Tang, J. Wang, Mater. Sci. Eng. A 640, 375 (2015)

[71] M. Jamshidinia, L. Wang, W. Tong, R. Kovacevic, J. Mater. Process. Technol. 214, 1728 (2014)

[72] S.J. Li, L.E. Murr, X.Y. Cheng, Z.B. Zhang, Y.L. Hao, R. Yang, F. Medina, R.B. Wicker, Acta Mater. 60, 793 (2012)

[73] L.E. Murr, S.M. Gaytan, F. Medina, E. Martinez, J.L. Martinez, D.H. Hernandez, B.I. Machado, D.A. Ramirez, R.B. Wicker, Mater. Sci. Eng. A 527, 1861 (2010)

[74] M.F. Ashby, Philos. Trans. R. Soc. A Math. Phys. Eng. Sci. 364, 15 (2006)

[75] V.S. Deshpande, M.F. Ashby, N.A. Fleck, Acta Mater. 49, 1035 (2001)

[76] J.C. Maxwell, Dublin Philos. Mag. J. Sci. 27, 294 (1864)

[77] E. Hernández-Nava, C.J. Smith, F. Derguti, S. Tammas-Williams, F. Léonard, P.J. Withers, I. Todd, R. Goodall, Acta Mater. 85, 387 (2015)

[78] A. Mortensen, Y. Conde, A. Rossoll, C.S. Marchi, J. Mater. Sci. 48, 8140 (2013)

[79] T.J. Horn, O.L.A. Harrysson, D.J. Marcellin-Little, H.A. West, B.D.X. Lascelles, R. Aman, Addit. Manuf. 1, 2 (2014)

[80] Z. Fang, B. Starly, W. Sun, Comput. Des. 37, 65 (2005)

[81] B. Starly, A. Lau, W. Sun, W. Lau, T. Bradbury, Comput. Des. 37, 387 (2005)

[82] J. Parthasarathy, B. Starly, S. Raman, J. Manuf. Process. 13, 160 (2011)

[83] M. Jamshidinia, L. Wang, W. Tong, R. Ajlouni, R. Kovacevic, J. Mater. Process. Technol. 226, 255 (2015)

[84] G. Epasto, G. Palomba, D.D. Andrea, E. Guglielmino, S. Di, F. Traina, Mater. Sci. Eng. A 753, 31 (2019)

[85] L. Yang, Rapid Prototyp. J. 21, 329e39 (2015)

[86] L. Xiao, W. Song, C. Wang, H. Tang, Q. Fan, N. Liu, J. Wang, Int. J. Impact Eng. 100, 75 (2017)

[87] M. Karl, J.R. Kelly, Dent. Mater. 25, 1426 (2009)

[88] M. Galati, P. Minetola, G. Rizza, Materials (Basel) 12, 2211 (2019)

[89] Y.Y. Sun, S. Gulizia, C.H. Oh, D. Fraser, M. Leary, Y.F. Yang, M. Qian, JOM 68, 791 (2016)

[90] M. Suard, P. Lhuissier, R. Dendievel, J.J. Blandin, F. Vignat, F. Villeneuve, Powder Metall. 57, 190 (2014)

[91] K.S. Chan, M. Koike, R.L. Mason, T. Okabe, Metall. Mater. Trans. A 44, 1010 (2013)

[92] ASTM, i, 1 (2019)

[93] S. Tammas-Williams, P.J. Withers, I. Todd, P.B. Prangnell, Scr. Mater. 122, 72 (2016)

[94] C. De Formanoir, S. Michotte, O. Rigo, L. Germain, S. Godet, Mater. Sci. Eng. A 652, 105 (2016) 